\title{
Individual Expectations, Limited Rationality and Aggregate Outcomes*
}

\author{
Te Bao ${ }^{\mathrm{a}}$, Cars Hommes ${ }^{\mathrm{a}}$, Joep Sonnemans ${ }^{\mathrm{a}, \mathrm{b}}$, and Jan Tuinstra ${ }^{\mathrm{a}}$ \\ ${ }^{a}$ CeNDEF, Department of Quantitative Economics, University of Amsterdam \\ Roetersstraat 11, 1018WB Amsterdam, NL \\ ${ }^{\mathrm{b}}$ CREED, Department of Economics, University of Amsterdam
}

Roetersstraat 11, 1018WB Amsterdam, NL

June 25, 2010

\begin{abstract}
Recent studies suggest that the type of strategic environment or expectation feedback can have a large impact on whether the market can learn the rational fundamental price. We present an experiment where the fundamental price experiences large unexpected shocks. Markets with negative expectation feedback (strategic substitutes) quickly converge to the new fundamental, while markets with positive expectation feedback (strategic complements) do not converge, but show under-reaction in the short run

${ }^{*}$ We thank the participants of seminars at the University of Amsterdam and Tinbergen Institute, of the 11th Workshop on Optimal Control, Dynamic Games and Nonlinear Dynamics, Amsterdam, May 31June 2, 2010, and the 1st LeeX International Conference on Theoretical and Experimental Macroeconomics, Barcelona, June 11-12, 2010, in particular John Duffy and Rosemarie Nagel, for stimulating discussions. Financial support from the EU 7th framework collaborative project Monetary, Fiscal and Structural Policies with Heterogeneous Agents (POLHIA) and Research Priority Area Behavioral Economics of the University of Amsterdam are gratefully acknowledged.
\end{abstract}


and over-reaction in the long run. A simple evolutionary selection model of individual learning explains these differences in aggregate outcomes.

JEL Classification: C92, G14, D84, D83, E37

Keywords: Expectation feedback, under- and overreaction, strategic substitutes and strategic complements, heuristic switching model, experimental economics 


\section{Introduction}

The rational expectation hypothesis ( $R E H$, Muth, 1961, Lucas, 1972) is a cornerstone of new classical economic analysis. According to this hypothesis, individuals use all available information and form expectations rationally. If all individuals in the economy have rational expectations, the market price converges to the rational expectation equilibrium $(R E E)$. Several studies have shown that, even when many agents violate the $R E H$ at the individual decision level, aggregation of individual behavior may enforce convergence of the market price to the REE (Becker, 1962, Smith, 1962, Gode and Sunder, 1993).

More recently it has been shown that depending on characteristic features of the market environment and institution, bounded rationality at the individual level may have a different impact on aggregate market behavior. For example, Haltiwanger and Waldman (1989) argued in a theoretical framework that under strategic complements agents have an incentive to mimic the strategy of the majority of others, magnifying the impact of irrational players and making convergence less likely; in contrast under strategic substitutes individuals have an incentive to do the opposite of what the others do, which makes the impact of irrational players smaller and enhances the likelihood of convergence. Fehr and Tyran (2002, 2005, 2008) studied the differences between environments with strategic complements and strategic substitutes by laboratory experiments. They set up an experiment on money illusion with a large anticipated shock, and investigate the speed of adjustment of nominal prices to the new equilibrium for different strategic environments. Their main finding is that the price in the strategic substitutes environment converges to the new equilibrium much more quickly than that in the strategic complements environment. As their experiment focuses on the role of money illusion, they provide the subjects with detailed information about the shock, so that the shock is fully anticipated.

Heemeijer et al (2009) ran "learning to forecast experiments (LtFE)" with human subjects to study whether the aggregation of individual expectations enforces convergence to

REE in markets with positive expectation feedback (and henceforth "positive feedback") and negative expectation feedback (and henceforth "negative feedback"). The realized market 
price is a function of average individual expectations, and the two market environments only differ in the sign of the expectations feedback. In a positive feedback market, the realized price will be high (low) when the individuals in the market predict it to be high (low), as is e.g. the case in demand driven speculative asset markets. In a negative feedback system the realized price is low (high) when the individuals in the market predict it to be high (low), as is e.g. seen in supply driven commodity markets with a production delay. In the context of LtFE, strategic complements is similar positive feedback, and strategic substitutes is similar to negative feedback. Heemeijer et al (2009) show that the difference in the type of expectation feedback alone leads to quite different aggregate price behavior when the underlying fundamental price (the $R E E$ ) is constant. They found that in the case of negative expectation feedback, the price quickly converges to the $R E E$, while in the case of positive expectation feedback, the market price is characterized by large fluctuations and persistent deviations from the fundamental.

The purpose of this paper is to study aggregate price behavior in positive and negative expectation feedback environment after large unanticipated shocks. There are three important informational differences with the experiments by Fehr and Tyran. Firstly, our subjects know qualitatively how the market works, but have no quantitative information about the market environment. From the qualitative information they should e.g. be able to infer whether there is positive respectively negative expectations feedback, but subjects do not know the exact specification of the price determination mechanism. In contrast, in Fehr in Tyran (2008) subjects have full information about the market, which they could use to calculate the pre-shock equilibrium price. Secondly, in Fehr and Tyran (2008) the shock is fully anticipated: subjects know when the shock take place and have enough information to compute the new, after-shock equilibrium price. In our LtFE, subjects are not informed about the exact timing of the shocks nor do they know the magnitude of the shocks. Thirdly, while in Fehr and Tyran (2008) subjects know the history of the behavior of their opponents, in our LtFE subjects are not informed about the forecasts of other individuals. They can only infer the behavior of other individuals through the aggregate market price. Our experiment should be seen as a stylized setting where individuals do not fully understand the complex 
market environment they are operating in and try to learn from observed aggregate prices. We are interested in the stability and convergence properties of the market as an aggregation mechanism of individual expectations, and whether after a large shock, individuals can learn the new fundamental price quickly. Our main finding is that negative feedback leads to quick adjustment to the new, after shock equilibrium, while in a positive feedback market price adjustment is very slow and characterized by initial underreaction followed by overreaction.

A second contribution of this paper is that we propose a model of heterogeneous individual expectations and learning to explain the different aggregate outcomes in positive and negative feedback markets. Our heuristic switching model is an extension of Brock and Hommes (1997), where subjects switch between different forecasting rules based upon their relative performance. In positive feedback markets trend following rules perform well and reinforce price oscillations leading to persistent deviations from RE equilibrium, and under and overreaction after a large shock. In negative feedback markets trend following rules perform poorly and are outperformed by simple adaptive expectations rule or contrarian rules, enforcing quick convergence to the new RE equilibrium.

The underreaction and overreaction found in the aggregate market price relate our experiment to the literature on overreaction and underreaction in financial markets (De Bondt and Thaler, 1985, Barberis et al, 1998). In financial economics overreaction and underreaction describe the reaction of stock prices to news about the firm's profitability. De Bondt and Thaler (1985) found from stock price data that people overreact to unexpected news about a firm's profitability in the sense that the price goes up (down) more than it does if people are using rational Bayesian updating. From the survey by Barberis et al (1998), it follows that stock prices underreact to news in the short run, in the sense that the change in profitability is slowly incorporated into the price, and overreact in the long run to consistent patterns of good or bad news in the sense that it may increase or decrease more than what can be justified by the news. Not much experimental work has been done on overreaction and underreaction. Although we are not directly testing overreaction and underreaction, our finding reproduces the characteristic features of financial markets documented by Barberis et al (1998), and suggests that the type of expectation feedback system may serve as a good 
explanation for this phenomenon. More recently Noussair and Powell (2009) noticed that in asset market, the pattern of movement in the fundamental price can influence market efficiency. They studied two kinds of pattern of fundamental price movement: Peak and Valley. Peak means the fundamental is increasing in the first half, and decreasing in the second, while Valley means it is decreasing in the first half, and increasing in the second. Based on an experimental setting similar to Smith et al (1998), they found that the market price tracked the fundamental better when the fundamental is a Peak than when it is a Valley. This result suggests that a changing fundamental price may generate results which are not trivially derived from the case when it is constant. The fundamental price in our study is similar to a Valley. Our findings suggest a negative feedback market can even track the fundamental very well when it is valley. Besides Fehr and Tyran (2008), our paper is related to other experimental work on the impact of strategic complements and strategic substitutes on the convergence of market price or level of coordination, such as Chen and Gazzale (2004), Potters and Suetens (2009). Our work is also related to the LtFEs with expectations feedbacks between individual forecasts and aggregate market prices in macroeconomic models, see e.g. Marimon and Sunder (1993, 1994), Marimon et al (1993), Adam (2007) and Pfajfar and Zakelj (2009), and in asset pricing models, Hommes et al (2005, 2008) and Sonnemans and Tuinstra (2008). Hommes (2010) gives a survey of learning to forecast experiments in macroeconomics and finance. Duffy (2008) gives a survey of both "learning to forecast" and "learning to optimize" ${ }^{1}$ experiments in macroeconomics.

The paper is organized as follows: Section 2 describes the experimental design. Section 3 presents the experimental results on aggregate market behavior as well as individual forecasting behavior. Section 4 presents a heuristic switching model explaining individual expectations as well as aggregate price behavior in both positive and negative feedback markets. Finally, section 5 concludes.

\footnotetext{
${ }^{1}$ Where in addition to making forecasts, the subjects also optimize and make transaction decisions.
} 


\section{Experimental Design}

\section{$2.1 \quad$ Treatments}

A computerized experiment was conducted in the CREED laboratory at the University of Amsterdam May 18-20, 2009. 16 experimental markets were created, half of them with positive feedback $\left(P_{1}, P_{2}, P_{3}, \ldots, P_{8}\right)$, and the other half negative feedback $\left(N_{1}, N_{2}, N_{3}, \ldots, N_{8}\right)$. There are 6 subjects in each experimental market. Subjects are asked to forecast the market price for 65 periods. The 65 periods are divided into 3 phases: period 1-20, 21-43 and 44-65. Figure 5 in the appendix shows the computer screen the subjects see during the experiment. In the appendix there are also experimental instructions for both treatments. Participants are shown the history of market prices and their own predictions, but not the predictions of others. The participants are provided qualitative information about the market, e.g. that the market price will increase (decrease) when there is excess demand (supply). Subjects are also informed that there may be large persistent changes in supply or demand, but they do not know when and how large the shocks will be. Before the experiment starts, participants are asked to answer four control questions to make sure that they understand the experiment.

\subsection{Expectation Feedback}

The expectation feedback system takes the simple form:

$$
p_{t}=f\left(\overline{p_{t}^{e}}\right)
$$

where $\overline{p_{t}^{e}}=\frac{1}{6} \sum_{h=1}^{6} p_{h, t}^{e}$ is the average price forecast of all subjects in the group (experimental market), and $f$ is a linear map.

For the negative feedback treatment the expectation feedback rule is given by:

$$
p_{t}=p_{t}^{*}-\frac{20}{21}\left(\overline{p_{t}^{e}}-p_{t}^{*}\right)+\epsilon_{t}
$$


For the positive feedback treatment the expectation feedback rule is given by:

$$
p_{t}=p_{t}^{*}+\frac{20}{21}\left(\overline{p_{t}^{e}}-p_{t}^{*}\right)+\epsilon_{t}
$$

Here $\epsilon_{t} \sim N(0,0.09)$ represents small demand/supply shocks. The (time varying) RE fundamental price in both treatments is given by $p_{t}^{*}$, which is:

$$
p_{t}^{*}= \begin{cases}56 & \text { when } 1 \leq t \leq 20 \\ 41 & \text { when } 21 \leq t \leq 43 \\ 62 & \text { when } 44 \leq t \leq 65\end{cases}
$$

The shifts in the RE equilibrium $p_{t}^{*}$ represent the large unexpected shocks in period 21 and 44. The two treatments are comparable, because they have the same REE, as well as the same absolute value of the slope of the linear feedback function. ${ }^{2}$ Because the absolute value of the slope is smaller than 1 , this REE $p_{t}^{*}$ is stable under naive expectations, which is if $p_{h, t}^{e}=p_{t-1}$ for all $h$.

\subsection{Individual Earnings}

Subjects are asked to make predictions about the future prices. They earn more money if their prediction is closer to the realized price. The individual earnings $\Pi_{h, t}$ per period are based on the quadratic prediction error:

$$
\Pi_{h, t}=\max \left\{1300-\frac{1300}{49}\left(p_{t}-p_{h, t}^{e}\right)^{2}, 0\right\}
$$

where 1300 points corresponds to 0.5 Euro, and the subjects will earn 0 if their prediction error is larger than 7. The experiment lasts for about 90 minutes, and the subjects' average earnings are about 30 euro.

\footnotetext{
${ }^{2}$ Heemeijer et al (2009) provides a microfoundation for the price adjustment rules (2) and (3), with demand and supply derived from wealth and profit maximization. The negative feedback market corresponds to a cobweb "hog-cycle" model, while the positive feedback market corresponds to an asset-pricing model with a market maker price adjustment rule. However, in their experiment the fundamental is a constant $\left(p_{t}^{*} \equiv 60\right)$ for all 50 periods.
} 


\section{Experimental Results}

\subsection{Aggregate Price Behavior}

Figure 1 plots the realized market price averaged over 8 markets (top panels), the price for each market (second panels) as well as the individual predictions in one typical market (bottom panels) in the case of positive feedback (left panels) and negative feedback (right panels) respectively. The RE equilibrium is represented by the dotted line.

The negative feedback markets generally make an almost perfect adjustment to the RE price after each large shock. The market experiences a short high volatility phase of about 3-5 periods, after which the prices neatly converge to the (new) rational expectations equilibrium price.

A Wilcoxon signed rank test is performed in the negative feedback markets to see whether the median of the market price is 56 in period 1-20, 41 in period 21-43, and 62 in period 44-65. We can not reject the null hypothesis that the median of the market price over time is equal to the rational expectation equilibrium in each group.

The results for the positive feedback markets are very different, as illustrated in Figure 1. Although the agents quickly coordinate on a common prediction from the very beginning of the experiment (see the time series of individual predictions), the market price does not quickly converge to equilibrium in the positive feedback markets.

A Wilcoxon signed rank test is performed on each positive feedback market to see whether the median of the market price is 56 in period 1-20, 41 in period 23-43, and 62 in period 44-65. The null hypothesis that the median of the market price over time is equal to the rational expectation equilibrium is rejected for 5 out 8 groups. ${ }^{3}$ This result confirms that for most of the positive feedback markets the market price does not converge to the REE.

Coordination of individual expectation and convergence towards the RE fundamental

\footnotetext{
${ }^{3}$ Groups $P_{1}, P_{2}, P_{4}, P_{5}$, and $P_{6}$.
} 

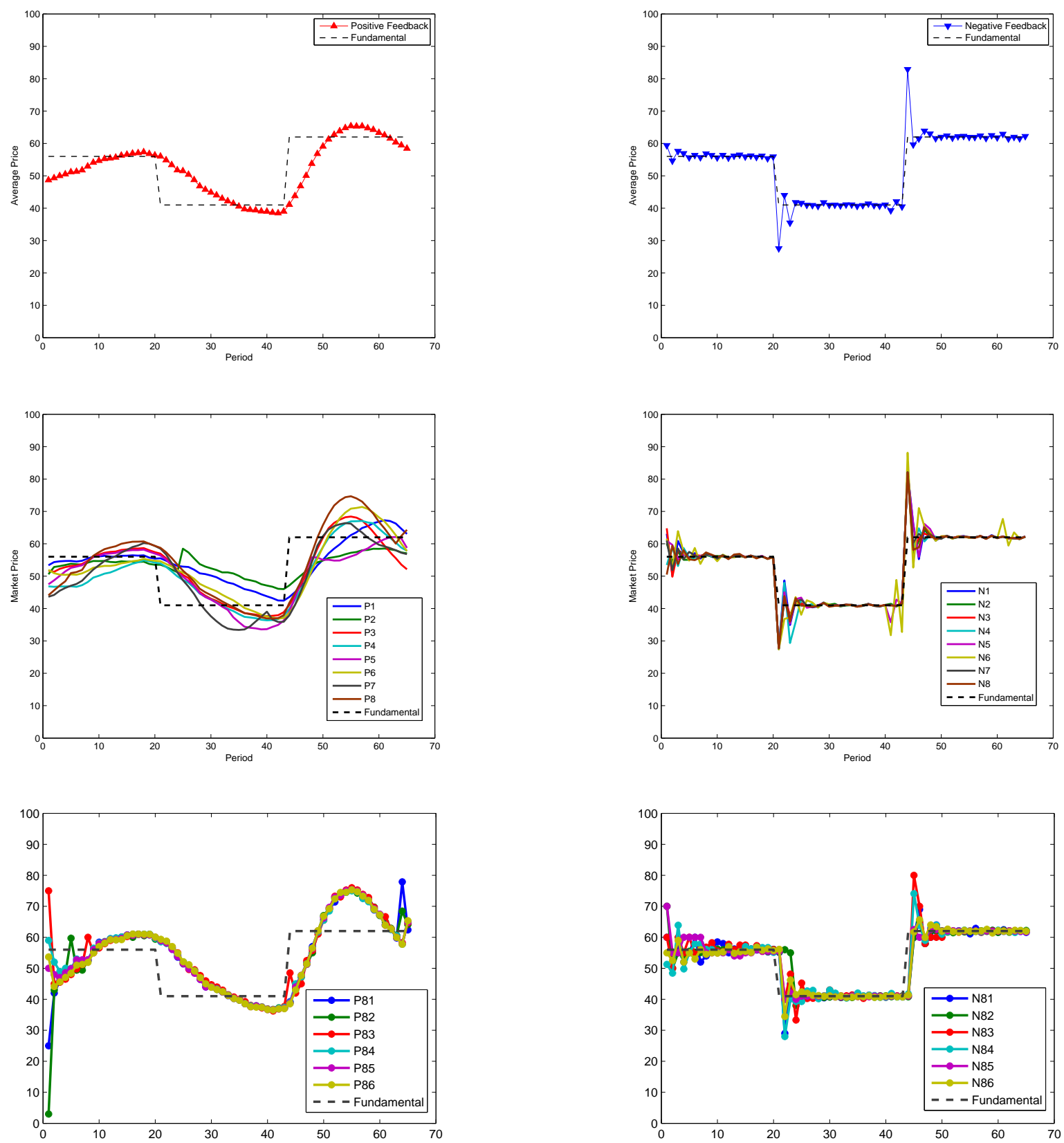

Figure 1: The average realized price over all groups (top panel), the market prices for different groups (middle panel) and individual predictions in group $P_{8}$ (bottom left) and group $N_{8}$ (bottom right) plotted together with fundamental price (dotted line). 
price is illustrated in Figure 2. The upper graph shows the distance between the fundamental price and the median of the market price over all groups, for both treatments. In the negative feedback treatment, after each large shock the median of the deviation of the market price from the fundamental quickly decreases to 0 and stays there during each phase. In contrast, in the positive feedback treatment, after each large shock, the deviation of the price from the fundamental decreases in a sluggish way, and even goes up occasionally during each phase. This behavior fits the description of stock prices by Barberis et al (1998), characterized by the underreaction at short and overreaction at longer time horizons. We find that the market price in the negative feedback treatment deviates from the fundamental price less (statistically significant at the $5 \%$ level by a paired sample sign test for all periods except period 1,2, 21 and 44), and therefore negative feedback markets exhibit a higher level of price convergence.

Another way to define convergence is to track whether the market price enters a small neighborhood of the fundamental price, for instance, the interval within the fundamental price plus or minus $3 \%$ and stays there. The intervals are [54.32, 57.68] for period 1 to 20 , [39.77, 42.23] for period 21 to 43 and $[60.14,63.86]$ for period 44 to 65 . We find that the market price in all groups in the negative feedback treatment converges to and stays within this $3 \%$ neighborhood within 5 periods, while none of the groups in the positive feedback treatment does.

Figure 2 also shows that there is little dispersion of individual predictions, as shown by the time series of the median over groups of the standard error of individual predictions in the bottom panel. A low standard deviation means that the participants in the same group have a high level of consensus on the future price. The median of the standard error of individual predictions is smaller in the positive feedback treatment in all periods during the first phase, in periods 22 to 32 in the second phase, and in periods 45 and 50 in the third phase. In the other periods the participants in the negative feedback also reach consensus because of the convergence of the market price to the RE equilibrium.

In summary, in the positive feedback market individuals quickly coordinate on a common 

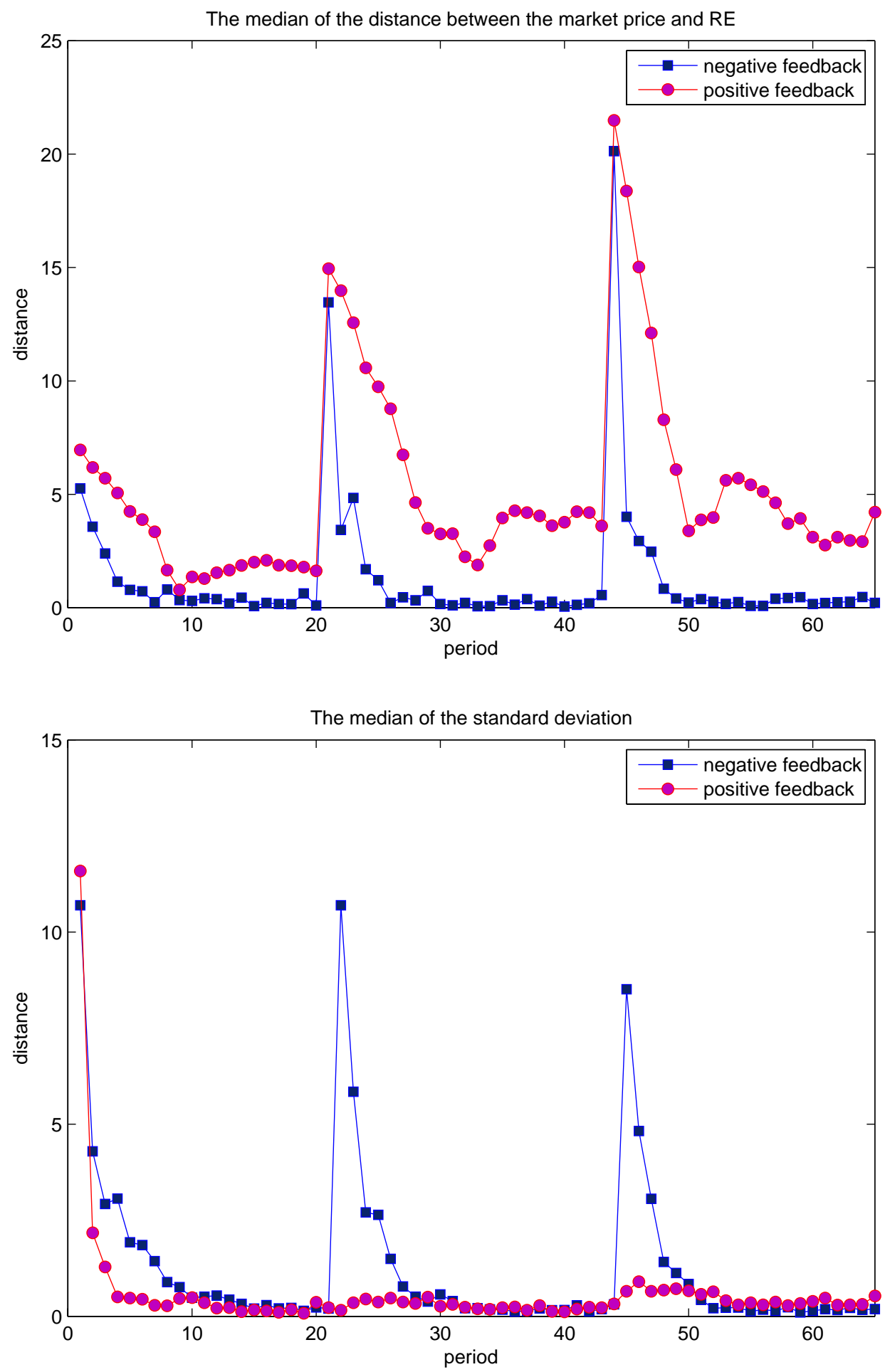

Figure 2: The upper graph shows the distance between the fundamental price and the median of the market prices from different groups. The lower graph shows the median of the standard deviations of the predictions in the different groups. The squares represent the negative feedback treatment, and the circles represent the positive feedback treatment. 
forecast, but they coordinate on a "wrong" non-equilibrium price. In the negative feedback

markets after a large shock some individuals disagree with the majority. Heterogeneity is more persistent, and stabilizes price dynamics. After that the price has converged and consensus about price prediction is achieved.

\subsection{Individual Prediction Rules}

\subsubsection{Rational expectations}

We compare the individual predictions with the REE for each of the three phases, using Wilcoxon signed rank tests (i.e. whether the median of each individual's prediction is 56 in period 1-20, 41 in period 21-43 and 62 in period 44-65). For the negative feedback markets the null hypothesis is rejected for 11 individuals in period 1-20, for 6 individuals in period 21-43 and for 11 individuals in period 44-65. For the positive feedback markets the null hypothesis is rejected for 20 individuals in period 1-20, 24 individuals in period 21-43 and 13 individuals in period 44-65. The number of individuals for whom we can not reject the null hypothesis for all periods is 26 out of 48 (more than 50\%) for the negative feedback markets and 9 out of 48 (less than 25\%) for the positive feedback markets.

This result suggests that it is not likely that most of the individuals predict the rational expectation equilibrium. The fact that there are more individuals for whom we can not reject the null hypothesis of rational expectations in the negative feedback markets suggests that it may be easier for the individuals to learn the REE in a negative feedback environment.

\subsubsection{Estimation of Linear Prediction Rules}

We estimate linear prediction rules used by the participants of the following form,

$$
p_{h, t}^{e}=c+\sum_{i=1}^{3} o_{i} p_{t-i}+\sum_{i=1}^{3} s_{i} p_{h, t-i}^{e}+\nu_{t}
$$

and find that the prediction rules of most participants can be captured by this simple rule very well. (i.e. with significant coefficients at the $5 \%$ level, high adjusted $R^{2}$, low MSE 
and no serial correlation.) Tables $A .1$ and $A .2$ in the appendix show the estimation result. We find that all estimated rules from the negative feedback have at least one significant coefficient, and 47 out of 48 rules from the positive feedback have at least one significant coefficient. The average adjusted $R^{2}$ is 0.9723 for the positive feedback and 0.9478 for the negative feedback. The average $M S E$ is 1.6828 for the positive feedback and 4.8318 for the negative feedback. The regressions suffer very little from serial correlation, as the residuals of the regressions do not have significant autocorrelation in the first 10 lags for 41 out of 48 rules in the negative feedback, and for 43 out of 48 rules in the positive feedback. Because the fundamental price is different in the three phases of this experiment, we need to check whether the econometric model is stable across the three phases, meaning that there is no structural break. We implement a Chow test on breakpoints to check the stability of the model. The breakpoints chosen are period 21 and 44, meaning that under the null hypothesis this econometric model is the same before the first shock, between the first and second shock, and after the second shock. Surprisingly, we reject the null hypothesis of no structural breaks for 44 out of 48 rules (around 92\%) in the negative feedback, and for 17 out of 48 rules (around 33\%) in the positive feedback. That means that about $2 / 3$ of all the subjects "observe" the shock and change their prediction rules, and the subjects in the negative feedback treatment are more likely to change their rules than the subjects in the positive feedback treatment. The explanation for this might be that in the negative feedback treatment the subjects usually have a very high chance to learn when the shock happens, and therefore adjust their prediction strategy accordingly. In contrast, in the positive feedback treatment the subjects coordinate on a common rule and learn the large shock only gradually, so it is less likely that they will change their prediction strategy abruptly.

\subsubsection{Estimation of Simple Heuristics}

The estimation result of linear rules with 3 lags in the last subsection shows that there is a lot of heterogeneity across individuals. We estimate some simpler (more restricted) rules. An advantage of these simpler rules or heuristics is that they allow for a behavioral interpretation. The estimation result is shown in Table A.3, A.4, A.5 and A.6 in the appendix 


\section{A.3.}

We consider two types of simple rules. The first type of simple rule is a trend rule, where the participants extrapolate a price change from the last observed price.

$$
p_{h, t-1}^{e}=p_{t-1}+\gamma\left(p_{t-1}-p_{t-2}\right)
$$

A positive coefficient $\gamma$ means a trend following rule, meaning that people expect a price increase when they see a previous increase; while a negative coefficient $\gamma$ means a contrarian rule, meaning that people expect a price decrease when they see a previous price increase. Table $A .3$ and $A .4$ show the estimation results of equation (6). For most individuals in the positive feedback treatment, the coefficient $\gamma$ is positive and in the range [0.4,1] and for most individuals in the negative feedback treatment, the coefficient $\gamma$ is negative and in the range $[-0.5,-0.2]$. This coefficient $\gamma$ is usually significant at the $5 \%$ level (it is significant for 44 out of 48 subjects in the negative feedback treatment, and for 45 out of 48 subjects in the positive feedback treatment), the adjusted $R^{2}$ for the significant models is large (it is on average 0.9890 for the positive feedback, and 0.9045 for the negative feedback) and the MSE of the regression is low (it is on average 0.8995 for the positive feedback, and 8.2069 for the negative feedback treatment). ${ }^{4}$

The second simple rule is the adaptive expectations rule:

$$
p_{h, t}^{e}=p_{t-1}^{e}+w\left(p_{t-1}-p_{t-1}^{e}\right)
$$

where the prediction is a weighted average of the previous prediction and the last observed price. Tables $A .5$ and $A .6$ show the estimation result of equation (7). The estimated coefficient $w$ is close to 1 for most subjects in the positive feedback treatment, and between 0.6-0.8 in the negative feedback treatment. This coefficient $w$ is significant at the $5 \%$ level for all individuals, the adjusted $R^{2}$ is large (it is on average 0.9488 for the positive feedback

\footnotetext{
${ }^{4}$ Most of the rules however do not pass the serial correlation test (the rules pass the test for serial correlation for only 17 out of 48 subjects (about 35\%) in the negative feedback, and 26 out of 48 subjects (about $55 \%$ ) in the positive feedback treatment).
} 
treatment, and 0.9159 for the negative feedback treatment) and the MSE of the regression is low (it is on average 3.2096 for the positive feedback treatment, and 7.8034 for the negative feedback treatment). ${ }^{5}$

The above results suggest that some of the subjects use simple forecasting heuristics.

\subsection{Benchmark Homogeneous Expectation Models}

Figure 3 shows the simulated price and prediction series if all the group members are using adaptive or trend rules. We take $w=0.85$ for the adaptive rule, $\gamma=0.9$ for the trend following rule, and $\gamma=-0.3$ for the contrarian rule, because these are the medians of the successful (significant, without serial correlation and structural break) rules we get from estimation. Figure 3 shows one-period ahead simulation with homogeneous expectations. In each period, the model imports the price data from the experiment so that the simulation is using the same history the human subjects in the laboratory experiment use. As is shown in the figure for one representative group in each treatment ${ }^{6}$, the contrarian rule fits best for the negative feedback treatment, and the trend following rule fits best for the positive feedback treatment treatment. However, none of these simple rules can describe the data pattern for all groups in the experiment.

These results suggest that similar subjects may use dissimilar heuristics in different situations. Moreover, they may switch between the different rules during the experiment. A model with evolutionary selection between these simple rules may therefore work well for these experimental data.

\footnotetext{
${ }^{5}$ Most of the rules can not pass the serial correlation test (the rules pass the test for serial correlation for only 5 out of 48 subjects (about 10\%) in the negative feedback treatment, and for 24 out of 48 subjects (about $50 \%$ ) in the positive feedback treatment).

${ }^{6}$ The same result holds for other groups in the same treatment.
} 

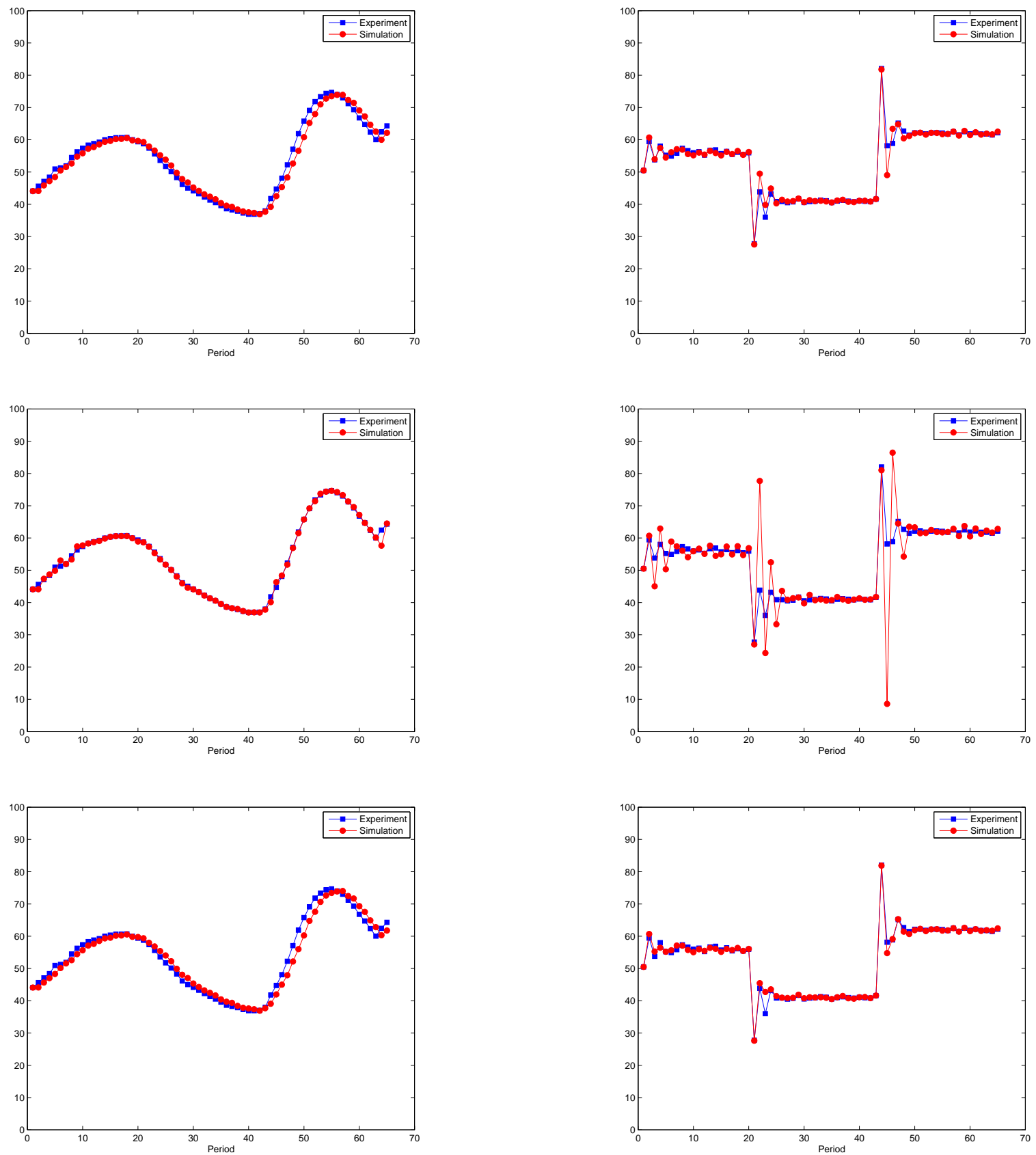

Figure 3: Experimental and simulated prices in the positive (left panel, group P8) and negative feedback treatment (right panel, group N8) under different homogeneous expectation rules: adaptive expectations (top panel), trend following rule (middle panel) and contrarian rule (bottom panel). The squares represent the price in experimental market, and the circles represent the one period ahead price forecast of the different prediction rules. 


\section{$4 \quad$ Heuristic Switching Models (HSM)}

Anufriev and Hommes (2009) provide a heuristic switching model, an extension of Brock and Hommes $(1997)^{7}$, which is able to explain substantially different price dynamics (monotonic convergence, persistent oscillations and dampened oscillations) in different groups in the asset pricing experiment of Hommes et al (2005). The key idea of the model is that the subjects chose between four simple heuristics depending upon their relative performance. The model is developed to explain the experimental data from a 2-period ahead LtFE asset pricing experiment (with positive feedback). There are two trend following rules in the model, a weak and a strong trend following rule. Since there is a negative feedback treatment in our experiment, we replace one trend following rule by a contrarian rule, which is able to detect short run up and down oscillation in negative feedback markets. The four rules in our model are therefore as follows:

An adaptive expectation (ADA) rule:

$$
p_{t+1,1}^{e}=p_{t}^{e}+0.85\left(p_{t}-p_{t, 1}^{e}\right)
$$

The contrarian rules (CTR) given by:

$$
p_{t+1,2}^{e}=p_{t}-0.3\left(p_{t}-p_{t-1}\right) .
$$

A trend extrapolating rule (TRE) given by:

$$
p_{t+1,2}^{e}=p_{t}+0.9\left(p_{t}-p_{t-1}\right)
$$

The fourth rule is called an anchoring and adjustment heuristic (A\&A), as in Tversky and Kahneman (1974):

$$
p_{t+1,4}^{e}=0.5\left(p_{t}^{a v}+p_{t}\right)+\left(p_{t}-p_{t-1}\right)
$$

The rule uses a time varying anchor, $0.5\left(p_{t}^{a v}+p_{t}\right)$, which is the average of the last price and the sample mean of all past prices, and extrapolates the last price change $p_{t}-p_{t-1}$. Because

\footnotetext{
${ }^{7}$ For related models on reinforcement learning, see e.g. Erev and Roth (1998) and Camerer and Ho (1999). Hommes (2010) discusses the differences between the different models.
} 
of its flexible time-varying anchor, the A\&A rule was successful in explaining persistent oscillations in Anufriev and Hommes (2009).

Subjects switch between these rules depending upon their relative performance. The performance of heuristic $h, h \in\{1,2,3,4\}$ is measured by the squared prediction error $^{8}$ :

$$
U_{t, h}=-\left(p_{t}-p_{t, h}^{e}\right)^{2}+\eta U_{t-1, h}
$$

and $n_{h, t}$ is the fraction of the agents using heuristic $h$ in the whole population. The parameter $\eta \in[0,1]$ shows the relative weight the agents give to past errors compared to the most recent one. When $\eta=0$, only the most recent performance is taken into account, and when $\eta>0$, all past errors matter for the performance. The specific weight updating rule is given by a discrete choice model with asynchronous updating from Hommes, Huang and Wang (2005) and Diks and van der Weide (2005):

$$
n_{t, h}=\delta n_{t-1, h}+(1-\delta) \frac{\exp \left(\beta U_{t-1, h}\right)}{\sum_{i=1}^{4} \exp \left(\beta U_{t-1, i}\right)} .
$$

The parameter $\delta \in[0,1]$ reflects the inertia with which participants stick to their rule. When $\delta=1$, the agents simply do not update. When $\delta>0$, each period a fraction of $1-\delta$ participants updates their weights. The parameter $\beta \geq 0$ represents the "sensitivity" to switch to another strategy. The higher the $\beta$, the faster the participants switch to more successful rules in the recent previous periods. When $\beta=0$, the agents will put equal weight on each rule. When $\beta=+\infty$, all agents who update switch to the most successful rule.

Figure 4 shows one period ahead simulation from this model, with parameter settings $\beta=0.4, \eta=0.7, \delta=0.9,\left[n_{1,1}, n_{1,2}, n_{1,3}, n_{1,4}\right]=[0.25,0.25,0.25,0.25]$, and the initial price as in the experiment. This simulation uses exactly the same parameters as in Anufriev and Hommes (2009), who fitted the model to a different experiment, as a benchmark simulation.

As shown in Figure 4, the HSM model fits the experimental data quite nicely. The evo-

\footnotetext{
${ }^{8}$ Note that the participants in this experiment were also paid according to the quadratic prediction errors.
} 

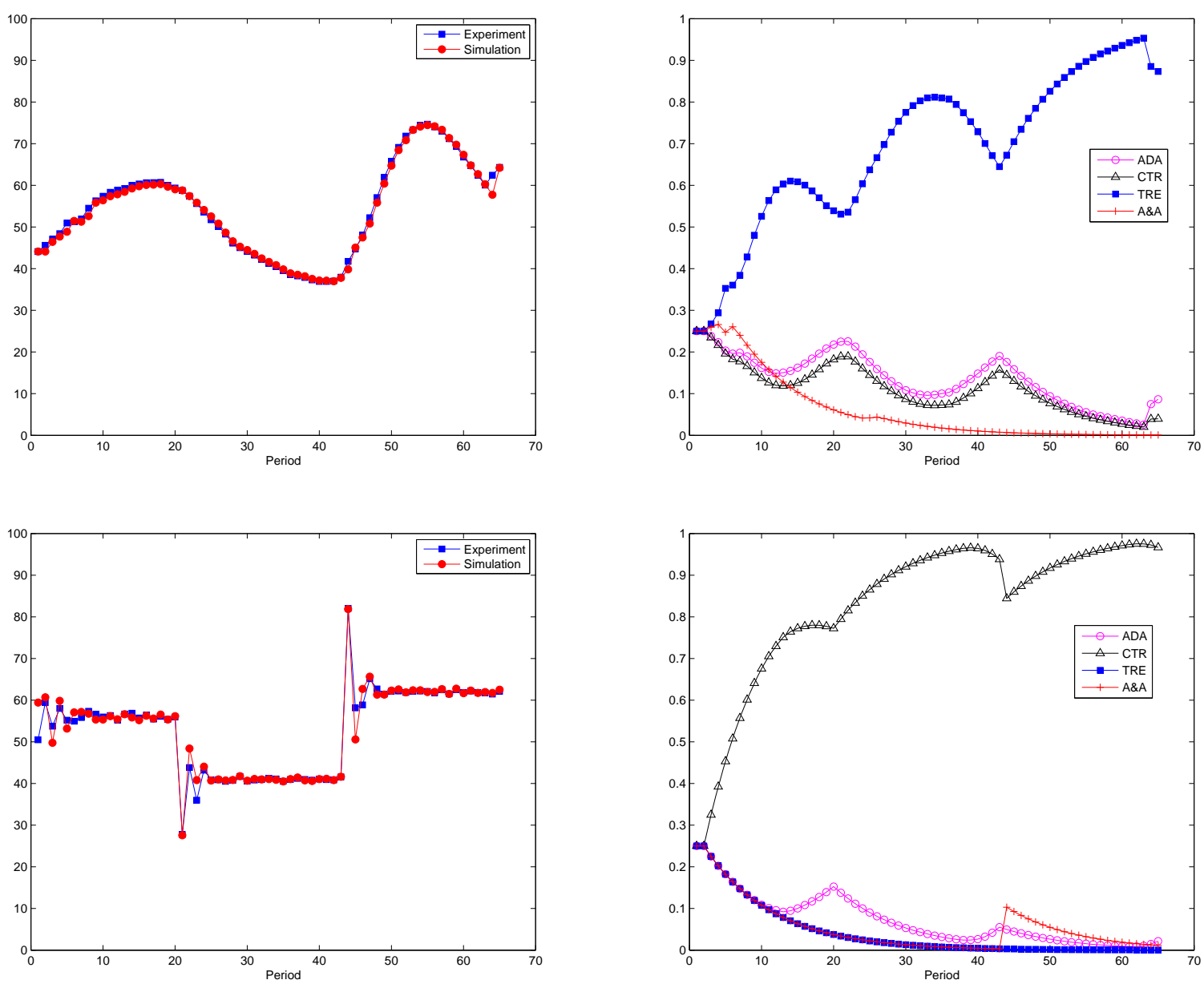

Figure 4: Experimental and simulated prices using HSM model in one typical group from the positive (top left, group P8) and negative feedback treatment (bottom left, group N8) respectively; blue squares are the experimental data, and red circles are simulated prices from the HSM model. The right panels show the evolution of market heuristics in the positive (top right) and negative feedback treatments (bottom right). The trend following rule dominates in the positive feedback markets, while the contrarian rule dominates in the negative feedback markets. 
lution of the forecasts using the different heuristics shows immediately that the dominating rules are different for the two treatments. In the negative feedback treatment the contrarian rule dominates, while in the positive feedback the trend following rule dominates. The weights of the rules also exhibit "kinks" around the period of the fundamental shocks, which suggest the subjects may adjust the weights on different strategies as a response to the shock.

We can compare the one period ahead forecast performance (Mean Squared Error) of this HSM model with other models. Table 1 shows the MSE of 9 different models: rational expectations, naive expectations, each of the homogeneous rules of the HSM and the three versions of the HSM. These versions are different in the choice of parameters $\beta, \eta$ and $\delta$. In the "HSM Benchmark" we use exactly the same parameter settings $\beta=0.4, \eta=0.7, \delta=0.9$ as in Anufriev and Hommes (2009). In the "HSM Experiment" we use a grid search to choose the parameters that minimize the total MSE of all groups in both treatments $(\beta=0.4, \eta=$ $0.9, \delta=0.9)$. Finally, in the "HSM Group" we use grid search to choose the parameters that minimize the MSE for each group independently (parameters are reported in Table 1).

The MSE are shown in Table 1, with the best model in bold. The rational expectation model does not perform well in both treatments. The contrarian rule performs well in the negative feedback markets, while it does not perform well in the positive feedback markets. In particular, the contrarian rule does relatively well in the initial periods after the shocks, since it is the only rule picking up the up and down oscillation of the negative feedback markets. The trend following rule performs well in the positive feedback markets, while it performs poorly in the negative feedback markets. The HSM Benchmark model already gives a very good fit. The HSM Group model gives the smallest MSE for 5 out of 8 groups in the positive feedback treatment, and 3 out of 8 groups in the negative feedback treatment. There is not too much difference between the HSM Experiment and HSM Group model, although the parameters might be quite different. This suggests that the HSM model is not very sensitive to parameterizations. The HSM model performs slightly worse than the contrarian rule in the negative feedback because the three other rules work poorly. The fact that the HSM beats the trend following rule in the positive feedback means although trend following is the rule with smallest MSE on average, there might still be some periods where other rules 


\begin{tabular}{|c|c|c|c|c|c|c|c|c|}
\hline Specification & $\mathrm{P} 1$ & $\mathrm{P} 2$ & P3 & $\mathrm{P} 4$ & $\mathrm{P} 5$ & $\mathrm{P} 6$ & $\mathrm{P} 7$ & $\mathrm{P} 8$ \\
\hline RE fundamental & 49.6788 & 59.0161 & 43.1575 & 48.5947 & 47.0988 & 55.0887 & 58.01 & 59.9699 \\
\hline naive & 0.4365 & 1.0085 & 1.6888 & 1.1457 & 1.3727 & 1.6121 & 2.3773 & 2.6978 \\
\hline $\mathrm{A} \& \mathrm{~A}$ & 9.2946 & 3.3583 & 17.0959 & 17.93 & 15.5062 & 19.8566 & 22.4779 & 26.9912 \\
\hline $\mathrm{ADA}$ & 0.6416 & 1.0312 & 2.3984 & 1.6715 & 1.8937 & 2.2959 & 3.3155 & 3.6962 \\
\hline CTR & 0.8198 & 1.111 & 2.9892 & 2.1113 & 2.3613 & 2.8641 & 4.1159 & 4.5494 \\
\hline TRE & 0.1237 & 2.0319 & 0.087 & 0.0711 & 0.4464 & 0.0766 & 0.3679 & 0.6186 \\
\hline HSM Benchmark & 0.124 & 1.0722 & 0.3299 & 0.2094 & 0.5857 & 0.2934 & 0.6281 & 0.8504 \\
\hline HSM Experiment & 0.0798 & 1.0738 & 0.1498 & 0.0961 & 0.5058 & 0.1257 & 0.4693 & 0.7081 \\
\hline HSM Group & 0.0575 & 1.0309 & 0.0803 & 0.0544 & 0.4512 & 0.0585 & 0.3622 & 0.6247 \\
\hline$\beta \in[0,10]$ & 0.4 & 5.0 & 0.9 & 0.6 & 0.9 & 0.7 & 0.4 & 10.0 \\
\hline$\eta \in[0,1]$ & 0.9 & 0.9 & 0.9 & 0.9 & 0.9 & 0.9 & 0.9 & 0.9 \\
\hline$\delta \in[0,1]$ & 0.7 & 0.9 & 0.0 & 0.0 & 0.0 & 0.0 & 0.0 & 0.5 \\
\hline Specification & N1 & $\mathrm{N} 2$ & N3 & N4 & N5 & N6 & N7 & N8 \\
\hline RE fundamental & 12.6053 & 10.1736 & 10.3248 & 13.1536 & 11.9303 & 22.3631 & 10.0034 & 10.4805 \\
\hline naive & 10.1551 & 5.9233 & 5.9417 & 9.2668 & 12.4492 & 15.4041 & 6.646 & 6.2231 \\
\hline $\mathrm{A} \& \mathrm{~A}$ & 83.8716 & 68.7025 & 71.8386 & 72.7769 & 80.2038 & 107.7959 & 67.9707 & 70.8805 \\
\hline $\mathrm{ADA}$ & 5.4345 & 2.5167 & 2.3009 & 5.8456 & 7.5808 & 10.4852 & 3.0471 & 2.6081 \\
\hline CTR & 3.0418 & 1.2676 & 0.9119 & 5.1556 & 4.9136 & 9.9613 & 1.7995 & 1.1486 \\
\hline TRE & 90.3862 & 72.7919 & 76.1975 & 82.4144 & 88.1665 & 133.8282 & 72.879 & 75.4719 \\
\hline HSM Benchmark & 6.8339 & 4.0172 & 4.3782 & 5.9768 & 7.5264 & 10.7787 & 4.1725 & 3.5143 \\
\hline HSM Experiment & 3.8852 & 1.937 & 2.4366 & 4.9945 & 5.0702 & 10.9711 & 2.2419 & 1.3874 \\
\hline HSM Group & 3.2117 & 1.9105 & 2.2515 & 4.9945 & 4.8011 & 9.3121 & 2.0943 & 1.2992 \\
\hline$\beta \in[0,10]$ & 0.4 & 0.6 & 0.6 & 0.4 & 0.4 & 0.4 & 0.6 & 0.6 \\
\hline$\eta \in[0,1]$ & 0.9 & 0.9 & 0.9 & 0.9 & 0.9 & 0.8 & 0.9 & 0.9 \\
\hline$\delta \in[0,1]$ & 0 & 0.9 & 0.5 & 0.9 & 0.8 & 0 & 0.5 & 0.5 \\
\hline
\end{tabular}

Table 1: MSE of the one-period ahead forecast for different groups in the positive (upper) and negative (lower) feedback treatment. HSM Benchmark means the HSM model with parameters $\beta=0.4, \eta=0.7, \delta=0.9$. HSM Experiment means the HSM model with parameters that give the best fit according to the average MSE of all groups in the both treatments, which is $\beta=0.4, \eta=0.9, \delta=0.9$. HSM Group means the HSM model with parameters that give the best fit according to the MSE for this group, with parameters $\beta, \eta, \delta$ shown in the bottom. 
can do better (meaning people are really using different rules in different periods). While the homogeneous contrarian rule does well in negative feedback markets and the trend following rule does well in positive feedback markets, the key point is that none of the homogeneous expectation model does well in both treatments.

In order to make an overall comparison we can calculate the average MSE in all groups of both treatments. The results are in Table 2. It is obvious that if we compare according to average MSE in both treatments, the HSM benchmark already performs well. HSM experiment outperforms all homogenous expectation models, which means it gives a very good description of the overall pattern of the data from the whole experiment. The parameter setting of HSM experiment is not very different from HSM benchmark, which also suggests that the HSM is not very sensitive to the parameters. HSM Group is the model with the best fit. The improvement (reduction of MSE) from the best homogenous agent model (homogenous model with the contrarian rule) to the best HSM is about $30 \%$.

\section{Conclusion and Discussion}

Testing the "rational expectation" hypothesis (Muth, 1961, Lucas, 1972) may actually mean two things: (1) to test whether the market price "reflects" the market clearing equilibrium when the equilibrium stays constant, (2) to test whether the market price quickly converges to the new equilibrium after large shocks to the fundamental price. We have shown that the type of expectation feedback is a key factor in how individual expectations and aggregate market prices respond to large unanticipated shocks. While in the negative feedback markets the price converges to the new equilibrium almost immediately perfectly, the positive feedback system generally moves towards the new equilibrium slowly, and moreover overshots the new fundamental. This fits the "underreaction at the beginning, and overreaction in the long run" story from empirical work on financial markets (see Barberis et al (1998)), and therefore suggests that the positive feedback feature of speculative asset market alone may be the main force that causes this phenomenon. 


\begin{tabular}{c||ccc}
\hline \hline Treatment & Positive & Negative & Both \\
\hline RE fundamental & 52.5768 & 12.6293 & 32.6031 \\
naive & 1.5424 & 9.0012 & 5.2718 \\
A\&A & 16.5638 & 78.0051 & 47.2844 \\
ADA & 2.1180 & 4.9774 & 3.5477 \\
CTR & 2.6153 & 3.5250 & 3.0701 \\
TRE & 0.4779 & 86.5170 & 43.4974 \\
HSM Benchmark & 0.5116 & 5.8997 & 3.2057 \\
HSM Experiment & 0.4010 & 4.1155 & 2.2583 \\
HSM Group & 0.3400 & 3.7344 & 2.0372 \\
\hline \hline
\end{tabular}

Table 2: The average MSE in negative feedback treatment, positive feedback treatment and both treatments (as an average of positive and negative feedback treatment) with 9 models. HSM Experiment means the HSM model with parameters that give the best fit according to the average MSE of all groups in both treatments, which is $\beta=0.4, \eta=0.9, \delta=0.9$. HSM Group means the HSM model with parameters that give the best fit according to the MSE of this group. 
The simulations of individual prediction rules show that neither rational expectation nor a homogeneous agent model with one simple heuristic is able to capture all the data from both treatments. Models with heterogeneous expectations and reinforcement learning, e.g. Brock and Hommes (1997), Branch (2004), and Anufriev and Hommes (2009) fit these experiments quite well. Agents switch between different prediction heuristics, based upon past forecast performance. In positive feedback markets the trend following rule performs well, thus reinforcing price trends and causing persistent deviations from the fundamentals. In negative feedback markets the trend following rule performs poorly and is outperformed by adaptive or contrarian rules, enforcing quick convergence to the new equilibrium. Future work should investigate whether this theory of expectation formation fits more complicated expectation feedback systems in finance and macroeconomics. 


\section{Bibliography}

1. Adam, K., "Experimental Evidence on the Persistence of Output and Inflation", Economic Journal, 117, 2007, 603-635.

2. Anufriev, M., and Hommes, C.H., "Evolutionary Selection of Individual Expectations and Aggregate Outcomes", CeNDEF Working paper, 2009.

3. Barberis, N., Shleifer,A., and Vishny, R., "A Model of Investor Sentiment", Journal of Financial Economics, 49, 1998, 307-343.

4. Becker, G., "Irrational Behavior and Economic Theory", Journal of Political Economy, 70, 1962, 1-13.

5. Brock, W.A., and Hommes, C.H. "A Rational Route to Randomness", Econometrica , 65, 1997, 1059-1095.

6. Brock, W.A., and Hommes, C.H., "Heterogeneous Beliefs and Routes to Chaos in a Simple Asset Pricing Model", Journal of Economics Dynamics and Control, 22, 1998, $1235-1274$.

7. Branch, W.A., "The Theory of Rationally Heterogeneous Expectations: Evidence from Survey Data on Inflation Expectations", Economic Journal, 114, 2004, 592-621.

8. Camerer, C., and Ho, T., "Experienced-Weighted Attraction Learning in Normal Form Games", Econometrica, 67, 1999, 827-874.

9. Chen, Y., and Gazzale, R., "When Does Learning in Games Generate Convergence to Nash Equilibria? The Role of Supermodularity in an Experimental Setting", American Economic Review, 94, 1505-1535.

10. De Bondt, W.F.M., and Thaler, R.H., "Does the Stock market Overreact?" Journal of Finance, 1985, 40, 793-805. 
11. Duffy, J., "Experimental Macroeconomics", Entry in: S. Durlauf and L. Blume, (Eds.), The New Palgrave Dictionary of Economics, 2nd ed., 2008, New York: Palgrave Macmillan.

12. Erev, I., and Roth, A.E., "Prediction How People Play Games: Reinforcement Learning in Games with Unique Strategy Equilibrium", American Economic Review, 88, 1998, 848-881.

13. Fehr, E., and Tyran, J.R. " "Does Money Illusion Matter?" American Economic Review, 91, 2002, 1239-1262.

14. Fehr, E., and Tyran, J.R. , "Individual Irrationality and Aggregate Outcomes," emphJournal of Economic Perspectives, 19, 2005, 43-66.

15. Fehr, E., and Tyran, J.R., "Limited Rationality and Strategic Interaction: the Impact of the Strategic Environment on Nominal Inertia", Econometrica, 76, 2008, 353-394.

16. Haltiwanger, J., and Waldman, M., "Rational Expectations and the Limits of Rationality: an Analysis of Heterogeneity" American Economic Review, 75, 1985, 326-340.

17. Heemeijer, P., Hommes, C.H., Sonnemans, J., and Tuinstra J., "Price Stability and Volatility in Markets with Positive and Negative Expectations Feedback: An Experimental Investigation", Journal of Economics Dynamics and Control, 33, 2009, 10521072.

18. Hommes, C.H., "The Heterogeneous Expectations Hypothesis: Some Evidence from the Lab", CeNDEF Working Paper, 2010.

19. Hommes, C.H., Sonnemans, J.H., Tuinstra, J. and van de Velden, H., "Coordination of Expectations in Asset Pricing Experiments", Review of Financial Studies, 18, 2005, 955-980.

20. Hommes, C.H., Sonnemans, J.H., Tuinstra, J., and van de Velden, H., "Expectations and Bubbles in Asset Pricing Experiments". Journal of Economic Behavior \& Organization, 67, 2008, 116-133. 
21. Marimon, R. and Sunder, S., "Indeterminacy of Equilibria in a Hyperinflationary World: Experimental Evidence", Econometrica, 61, 1993, 1073-1107.

22. Marimon, R., and Sunder, S., "Expectations and Learning under Alternative Monetary Regimes: An Experimental Approach", Economic Theory, 4, 1994, 131-62.

23. Marimon, R., Spear S. E. and Sunder, S., "Expectationally Driven Market Volatility: An Experimental Study", Journal of Economic Theory, 61, 1993, 74-103.

24. Noussair, C. N., and Powell, O., "Peaks and Valleys: Price Discovery in Experimental Asset markets with Non-Monotonic Fundamental", Journal of Economic Studies, 2009, forthcoming.

25. Pfajfar, D., and Zakelj, B., "Experimental Evidence on Inflation Expectation Formation", CentER Discussion Paper, 2009.

26. Potters, J., and Suetens, S., "Cooperation in Experimental Games of Strategic Complements and Substitutes", Review of Economic Studies, 76, 2009, 1125-1147.

27. Smith, V. L., Suchanek. G.L., and Williams, A.W., "Bubbles, Crashes, and Endogenous Expectations in Experimental Spot Asset Markets", Econometrica, 56, 1988, 1119-1151.

28. Sonnemans, J., and Tuinstra, J., "Positive Expectations Feedback Experiments and Number Guessing Games as Models of Financial Markets", CeNDEF Working paper, 2008.

29. Tversky, A., and Kahneman, D., "Judgement under Uncertainty: Heuristics and Biases," Science, 185, 1974, 1124-1130. 


\section{A Appendix}

\section{A.1 Experimental instructions (for negative feedback)}

\section{General information}

In this experiment you participate in a market. Your role in the market is an advisor of a large firm, and the firm is a major Producer of one product sold in the market. In each period the firm asks you to make a prediction of the market price of the product. The price should be predicted one period ahead, since producing the good takes some time. You are going to advise the firm for 65 successive time periods. For each period you have to make a prediction for the price in the next period. Your earnings from the experiment will depend on the accuracy of your predictions. The smaller your prediction error is, the greater your earnings are.

\section{About the market}

The price of the product will be determined by the law of supply and demand. The supply on the market is determined by the production decision of the producers. There are several large producers on this market and each of them is advised by a participant of this experiment. Higher price predictions make a producer produce a larger quantity, which increases the supply and vise versa. Total supply is largely determined by the sum of the individual supplies of these producers, although there may be small random fluctuations caused by transportation delay or other reasons.

The size of the demand depends upon the price. When the price goes up, the demand

will go down. In some periods there may be large persistent changes in the demand, caused by demand from other international markets or other reasons.

About the price determination

The price is determined as follows. If total demand is larger than total supply, the price will rise. Conversely, if total supply is larger than total demand, the price will fall. 


\section{About the price prediction}

The only task of the advisors in this experiment is to predict the market price in each time period as accurately as possible. Your prediction should always lie between 0 and 100 euros in the each period. At the beginning of the experiment you are asked to give a prediction for the price period 1. When all participants have submitted their predictions for the first period, the market price for period 1 will be made public. Based on the prediction error in period 1, which is the difference between the market price and your prediction, your earnings in the first period will be calculated. The larger your prediction error is, the less earning you are going to make for this period. Subsequently, you are asked to enter your prediction for period 2. When all participants have submitted their prediction for the second period, the market price for that period, will be made public and your earnings will be calculated, and so on, for all 65 consecutive periods. The information you can refer to form at period t consists of all previous prices, your predictions and earnings.

\section{About the earnings}

Your earnings depend only on the accuracy of your predictions. The earnings shown on the computer screen will be in terms of points. The maximum possible points you can make for each period (if you make no prediction error) is 1300, and the larger your prediction error is, the fewer points you can make. You will earn 0 points if your prediction error is larger than 7. There is a Payoff Table on your table, which shows the points you can earn for different prediction errors. For example, your prediction was 13.42. The true market price turned out to be 12.13 . This means that the prediction error is: $13.42-12.13 \approx 1.30$. The table then says your earnings are 1255 credits (as listed in the first column).

We will pay you in cash at the end of the experiment based on the points you earned. You earn 0.5 euro for each 1300 points you make. 


\section{A.2 Experimental instructions (for positive feedback)}

In our experiment the experimental instructions are exactly the same for positive and negative feedback treatments except the part "General information" and "About the market". The paragraphs of "General information" and "about the market" for positive feedback are as follows:

\section{General information}

In this experiment you participate in a market. Your role in the market is an advisor of a trading company who is active on a market for a certain product. In each time period the trading company needs to decide how many units of the product he will buy, intending to sell them again the next period. To take an optimal decision, the company asks you to make a prediction of the market price of the product during 65 successive time periods. Your earnings during the experiment will depend on the accuracy of your predictions. The smaller your prediction error is, the greater earnings you will get at the end of the experiment.

\section{About the market}

The price of the product will be determined by the law of supply and demand. Supply and demand on the market are determined by the trading companies (you are advising one of them) of the product. Higher price predictions make a trading company demand a larger quantity and vise versa. A high price prediction also makes the trading company less willing to sell the product in this period, which decreases the supply and vise versa. There are several large trading companies active on this market and each of them is advised by a participant of this experiment.

Total supply and demand is largely determined by the sum of the individual supplies and demands of these companies. There are two kinds of exogenous shocks which may affect the total supply and demand: (1) in each period, there may be small random fluctuations in the supply caused by transportation delay or other reasons. (2) In some periods, there may large persistent changes in the demand caused by demand from other international markets or other reasons. 
Computer instructions (Please read this after you finish the check questions)

During the experiment your computer screen will look like this, please read instruction (1)-(3) carefully:

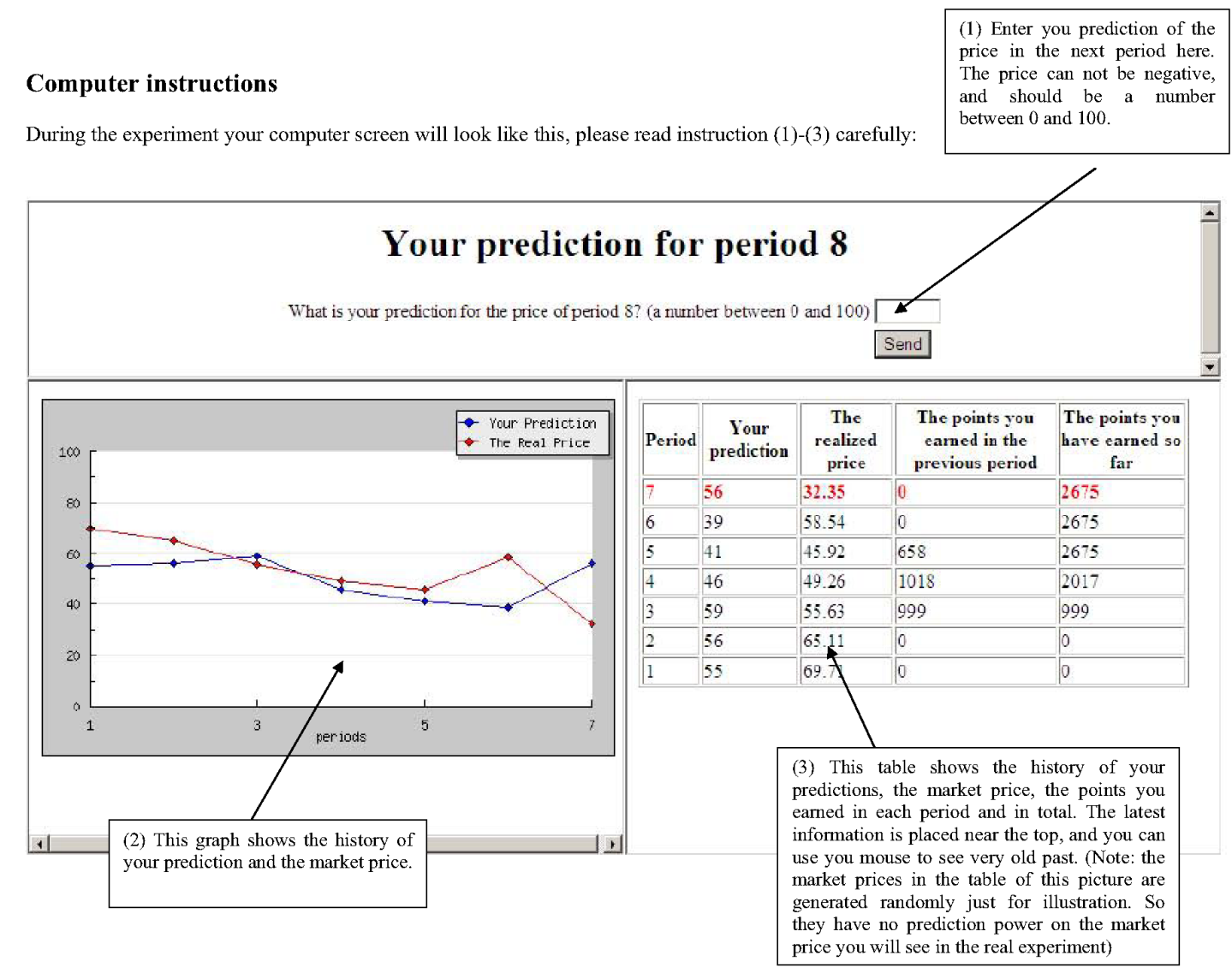

Figure 5: The computer screen during the experiment.

In the mini-page at the top you can submit your prediction of the price in the next period. The title "You Prediction for period XX" will tell you for which period you are predicting. You have to enter your prediction as a number between 0 and 100. You can use numbers with at most 2 digits after the decimal point (for example, 25, 34.7 and 55.66). Please DO use the decimal point ("."), NOT comma (",") when you want to use decimal numbers.

After you made your prediction please press "send" to submit. You might need to wait for other participants in the same market before continuing to the next period. The market 
price for the next period will be calculated once all the members in the same market have submitted their predictions. Then you continue with the prediction in the next period for the price in the period after the next period, and so on

The graph in the left hand side below the prediction window shows the history of your prediction and the market price. The table in the right hand side below the prediction window shows the history of your prediction, the market price, as well as the point you earned in each period and in total. The more recent information is put closer to the top. You can use your mouse and the stroller to trace the information in older past.

The graph and the table will be updated in the beginning of each new period. Please notice that the price and prediction information in the above graph and table is just for illustration. The data are generated randomly. So it does not have any implication on what will really happen in our experiment.

When everyone finishes the instructions and the check questions, we will begin the ex-

periment. If you have questions now or during the experiment, raise your hand. Someone will come to you for assistance.

\section{A.3 Results of Estimation of Individual Prediction Rules}




\begin{tabular}{|c|c|c|c|c|c|c|c|c|c|c|c|}
\hline No. & $C$ & $p_{-1}^{e}$ & $p_{-2}^{e}$ & $p_{-3}^{e}$ & $p_{-1}$ & $p_{-2}$ & $p_{-3}$ & $R^{2}$ & MSE & Chow & $\mathrm{AC}$ \\
\hline exp11 & 0 & 0.4622 & 0 & 0 & 0.647 & 0 & 0 & 0.9611 & 3.8061 & $\mathrm{Y}$ & $\mathrm{N}$ \\
\hline exp12 & 0 & -0.24 & 0 & 0 & 0.6394 & 0.448 & 0 & 0.9528 & 4.2924 & Y & $\mathrm{N}$ \\
\hline exp13 & 0 & -0.3457 & 0 & 0 & 0.4103 & 0.6421 & 0.1889 & 0.9789 & 1.8968 & Y & $\mathrm{N}$ \\
\hline exp14 & 0 & 0.6054 & 0 & 0 & 0.3871 & 0 & 0 & 0.9541 & 3.5275 & Y & $\mathrm{N}$ \\
\hline exp15 & 0 & -0.5303 & 0 & 0.2836 & 0.3934 & 0.5331 & 0.2948 & 0.9594 & 3.5433 & Y & $\mathrm{N}$ \\
\hline exp16 & 0 & 0 & 0 & -0.1405 & 0.7417 & 0.2772 & 0 & 0.9614 & 3.9787 & Y & $\mathrm{N}$ \\
\hline exp21 & 0 & 0.464 & 0 & 0 & 0.7071 & 0 & 0 & 0.9586 & 3.7491 & Y & $\mathrm{N}$ \\
\hline exp22 & 0 & 0.4538 & 0 & 0 & 0.5028 & 0.2493 & -0.1455 & 0.9963 & 0.3333 & Y & $\mathrm{Y}$ \\
\hline exp23 & 0 & 0.4356 & -0.2405 & 0.1253 & 0.7322 & -0.2315 & 0.1828 & 0.99 & 0.8982 & Y & $\mathrm{N}$ \\
\hline exp24 & 0 & 0 & 0 & 0.0603 & 0.7102 & 0.4216 & 0 & 0.9815 & 1.7375 & Y & $\mathrm{N}$ \\
\hline exp25 & 0 & 0.4352 & 0 & 0 & 0.2214 & 0.2962 & 0 & 0.9258 & 6.1082 & Y & $\mathrm{N}$ \\
\hline exp26 & 0 & 0.2842 & 0 & 0.0967 & 0.9312 & -0.3726 & 0.1704 & 0.9918 & 0.8104 & Y & $\mathrm{N}$ \\
\hline exp31 & 0 & -0.1964 & -0.2181 & 0.1008 & 0.8384 & 0.3108 & 0 & 0.9805 & 1.8719 & Y & $\mathrm{N}$ \\
\hline exp32 & 0 & 0.4275 & 0 & 0 & 0.3867 & 0 & 0 & 0.9607 & 3.1034 & $\mathrm{Y}$ & $\mathrm{N}$ \\
\hline exp33 & 0 & 0.62 & -0.3234 & 0.0843 & 0.7522 & -0.2415 & 0 & 0.9911 & 0.8506 & Y & $\mathrm{Y}$ \\
\hline exp34 & 0 & 0.2655 & 0 & -0.0727 & 0.7056 & 0 & -0.0938 & 0.9985 & 0.1363 & Y & Y \\
\hline exp35 & 0 & 0.6708 & 0 & 0 & 0.4036 & -0.1087 & 0 & 0.9588 & 3.0188 & Y & $\mathrm{N}$ \\
\hline exp36 & 0 & 0 & 0 & 0 & 0.6343 & 0.2686 & 0 & 0.9572 & 4.2695 & Y & $\mathrm{N}$ \\
\hline exp41 & 0 & 0.9632 & -0.5815 & 0.1789 & 0.8975 & -0.8803 & 0.394 & 0.9645 & 3.2426 & $\mathrm{Y}$ & $\mathrm{N}$ \\
\hline exp42 & 0 & 0.538 & -0.2784 & 0 & 0.2498 & 0.2249 & 0.1284 & 0.9422 & 5.0076 & Y & $\mathrm{N}$ \\
\hline exp43 & 0 & 0.2415 & -0.2837 & 0.3586 & 0.7107 & -0.3372 & 0.2976 & 0.8642 & 13.7563 & $\mathrm{~N}$ & $\mathrm{~N}$ \\
\hline exp44 & 0 & 0.2505 & -0.3411 & 0.2615 & 0.6192 & 0 & 0.1956 & 0.9591 & 3.6552 & $\mathrm{Y}$ & $\mathrm{N}$ \\
\hline $\exp 45$ & 0 & 0.3244 & 0 & 0 & 0.7681 & 0 & 0 & 0.9664 & 3.1572 & Y & $\mathrm{N}$ \\
\hline exp46 & 0 & 0 & 0 & 0 & 0.5798 & 0 & 0 & 0.9359 & 5.2838 & $\mathrm{Y}$ & $\mathrm{N}$ \\
\hline exp51 & 0 & 0 & 0.1336 & 0.1595 & 0.4755 & 0.3884 & 0 & 0.9572 & 3.6324 & $\mathrm{Y}$ & $\mathrm{Y}$ \\
\hline exp52 & 0 & 0 & 0 & 0.1458 & 0.6134 & 0.1615 & 0 & 0.9548 & 3.971 & Y & $\mathrm{N}$ \\
\hline exp53 & 0 & 0 & 0.2501 & 0 & 0.0635 & 0.4535 & 0.2991 & 0.9755 & 2.1254 & Y & $\mathrm{Y}$ \\
\hline exp54 & 0 & -0.3746 & 0 & 0.154 & 0.5987 & 0.4135 & 0.2705 & 0.9457 & 5.0186 & Y & Y \\
\hline $\exp 55$ & 0 & 0 & 0 & 0.106 & 0.6287 & 0.2335 & 0 & 0.9731 & 2.3915 & Y & $\mathrm{N}$ \\
\hline $\exp 56$ & 0 & 0 & 0 & 0 & 0.6365 & 0.3284 & 0 & 0.8156 & 19.0925 & $\mathrm{~N}$ & $\mathrm{~N}$ \\
\hline exp61 & 0 & -0.2057 & 0 & 0.3473 & 0.4015 & 0.2203 & 0.1926 & 0.9185 & 7.3438 & $\mathrm{Y}$ & $\mathrm{N}$ \\
\hline exp62 & 0 & 0.3444 & -0.2242 & 0.2469 & 1.0738 & -0.548 & 0 & 0.9472 & 6.3421 & Y & $\mathrm{N}$ \\
\hline exp63 & 0 & 0.4328 & 0 & 0.1801 & 0.8452 & -0.4299 & 0 & 0.9622 & 3.9672 & Y & $\mathrm{N}$ \\
\hline exp64 & 6.7799 & 0 & 0 & 0 & 0.9524 & 0 & 0 & 0.8199 & 24.875 & $\mathrm{~N}$ & $\mathrm{~N}$ \\
\hline exp65 & 0 & 0 & 0 & 0 & 0 & 0.3765 & 0.299 & 0.6299 & 39.7841 & $\mathrm{~N}$ & $\mathrm{~N}$ \\
\hline exp66 & 0 & 0 & 0 & 0.3641 & 0.1507 & 0.1522 & 0.2187 & 0.9269 & 5.6884 & $\mathrm{Y}$ & $\mathrm{N}$ \\
\hline exp71 & 0 & 0 & 0 & 0.2288 & 0.6091 & 0 & 0.2577 & 0.9644 & 3.0881 & Y & $\mathrm{N}$ \\
\hline exp72 & 0 & 0 & 0 & 0.1363 & 0.6493 & 0 & 0.1835 & 0.9659 & 2.9821 & Y & $\mathrm{N}$ \\
\hline $\exp 73$ & 0 & 0 & 0 & 0.1062 & 0.6551 & 0.2641 & 0.1113 & 0.9955 & 0.3976 & $\mathrm{Y}$ & $\mathrm{N}$ \\
\hline exp74 & 0 & 0 & 0 & 0.0931 & 0.6801 & 0 & 0 & 0.9836 & 1.3959 & Y & $\mathrm{N}$ \\
\hline $\exp 75$ & -1.1827 & 0.1989 & 0 & 0 & 0.5264 & 0.36 & -0.0832 & 0.9955 & 0.4197 & $\mathrm{Y}$ & $\mathrm{N}$ \\
\hline exp76 & 0 & 0.4835 & -0.3622 & 0.1862 & 0.3511 & 0 & 0.2607 & 0.9746 & 2.0488 & Y & $\mathrm{N}$ \\
\hline exp81 & 0 & -0.3883 & -0.2326 & 0.1181 & 0.6122 & 0.5739 & 0.2967 & 0.965 & 3.19 & Y & $\mathrm{N}$ \\
\hline exp82 & 0 & 0.3897 & 0 & 0 & 0.3313 & 0.1371 & 0.1519 & 0.946 & 4.2728 & Y & $\mathrm{N}$ \\
\hline exp83 & 0 & 0 & 0 & 0 & 0.8386 & 0 & 0 & 0.9632 & 3.5895 & Y & $\mathrm{N}$ \\
\hline exp84 & 0 & -0.193 & -0.2321 & 0 & 0.8515 & 0.3506 & 0.185 & 0.9854 & 1.4175 & Y & Y \\
\hline exp85 & 0 & 0.553 & -0.2257 & 0.1283 & 0.5193 & 0 & 0 & 0.989 & 0.9377 & Y & Y \\
\hline exp86 & 0 & 0 & 0 & 0 & 0.5768 & 0.304 & 0 & 0.9775 & 1.9208 & Y & $\mathrm{N}$ \\
\hline
\end{tabular}

Table A.1: Above is the result for estimating $p_{h, t}^{e}=c+\sum_{i=1}^{3} o_{i} p_{t-i}+\sum_{i=1}^{3} s_{i} p_{h, t-i}^{e}+\nu_{t}$ for the negative feedback treatment. The first column shows the participant number. The second to eights column shows the estimated coefficients. We start from the largest possible model and drop all the coefficients that are not significant at $5 \%$ level. The ninth and tenth columns show the $R^{2}$ and $M S E$ of the regressions. The twelfth shows whether we reject the null hypothesis of no breakpoint in the Chow test. 


\begin{tabular}{|c|c|c|c|c|c|c|c|c|c|c|c|}
\hline No. & $C$ & $p_{-1}^{e}$ & $p_{-2}^{e}$ & $p_{-3}^{e}$ & $p_{-1}$ & $p_{-2}$ & $p_{-3}$ & $R^{2}$ & MSE & Chow & $\mathrm{AC}$ \\
\hline exp11 & 0 & 0 & 0 & 0 & 1.3677 & 0 & -0.2909 & 0.9975 & 0.121 & $\mathrm{~N}$ & $\mathrm{~N}$ \\
\hline exp12 & 1.1632 & 0.556 & 0 & 0 & 1.3571 & -0.9944 & 0 & 0.9984 & 0.0765 & Y & $\mathrm{N}$ \\
\hline exp13 & 0 & 0.2726 & 0 & 0 & 1.4246 & -0.6749 & 0 & 0.9989 & 0.0529 & $\mathrm{~N}$ & $\mathrm{~N}$ \\
\hline exp14 & 0 & 0 & 0 & 0 & 1.8891 & $\begin{array}{l}-1.4069 \\
\end{array}$ & 0 & 0.9973 & 0.1274 & $\mathrm{~N}$ & $\mathrm{~N}$ \\
\hline exp15 & 0 & 0.4342 & 0 & 0 & 1.3325 & -0.8467 & 0 & 0.9986 & 0.0704 & $\mathrm{~N}$ & $\mathrm{~N}$ \\
\hline exp16 & 1.0477 & 0.8928 & 0.119 & -0.0692 & 1.2435 & -1.3469 & 0 & 0.999 & 0.048 & Y & $\mathrm{Y}$ \\
\hline $\exp 21$ & 0.5901 & 0.561 & 0 & 0.0242 & 1.6833 & -1.5427 & 0.297 & 0.9988 & 0.0162 & $\mathrm{Y}$ & $\mathrm{N}$ \\
\hline exp22 & 0 & 0 & 0 & 0 & 0 & 0 & 0 & 0.1874 & 36.4388 & $\mathrm{~N}$ & $\mathrm{~N}$ \\
\hline exp23 & 0 & 0.4998 & 0 & -0.1976 & 1.4443 & -1.144 & 0.3596 & 0.9908 & 0.1151 & Y & $\mathrm{N}$ \\
\hline exp24 & 0 & 0.4537 & -0.1405 & 0.1113 & 0.6647 & 0 & -0.1851 & 0.9913 & 0.0968 & $\mathrm{Y}$ & $\mathrm{Y}$ \\
\hline exp25 & 3.4909 & 0.3665 & 0 & 0 & 0.731 & 0 & 0 & 0.9266 & 0.7579 & $\mathrm{~N}$ & $\mathrm{~N}$ \\
\hline $\exp 26$ & 1.6552 & 0 & 0 & -0.0417 & 1.0412 & 0 & -0.1203 & 0.9968 & 0.0353 & $\mathrm{Y}$ & $\mathrm{Y}$ \\
\hline exp31 & 0.5881 & 0.3303 & 0 & -0.0625 & 1.6603 & -1.2094 & 0 & 0.9987 & 0.1127 & $\mathrm{~N}$ & $\mathrm{~N}$ \\
\hline exp32 & 0 & -0.292 & 0 & -0.1666 & 2.2084 & -0.9762 & 0 & 0.9985 & 0.1305 & $\mathrm{Y}$ & $\mathrm{N}$ \\
\hline exp33 & 1.0534 & 0 & 0 & 0 & 1.3029 & 0 & -0.4897 & 0.9949 & 0.4537 & $\mathrm{~N}$ & $\mathrm{~N}$ \\
\hline exp34 & 0.6943 & 0 & 0 & 0 & 1.9112 & -1.0784 & 0 & 0.9985 & 0.1284 & $\mathrm{~N}$ & $\mathrm{~N}$ \\
\hline exp35 & 0.5784 & 0.354 & 0 & 0 & 1.7423 & -1.2642 & 0 & 0.9989 & 0.0953 & $\mathrm{Y}$ & $\mathrm{N}$ \\
\hline exp36 & 0 & 0 & 0 & 0 & 1.2791 & 0 & -0.2964 & 0.9973 & 0.2419 & $\mathrm{Y}$ & $\mathrm{N}$ \\
\hline exp41 & 0 & 0.4202 & 0 & 0 & 1.6719 & -1.3097 & 0 & 0.9986 & 0.1291 & $\mathrm{~N}$ & $\mathrm{~N}$ \\
\hline exp42 & 0 & 0.423 & 0 & 0 & 1.9483 & -1.8616 & 0.4256 & 0.9993 & 0.0601 & $\mathrm{Y}$ & $\mathrm{N}$ \\
\hline exp43 & 0 & 0 & 0 & 0 & 1.7329 & -0.8071 & 0 & 0.9992 & 0.0691 & $\mathrm{Y}$ & $\mathrm{N}$ \\
\hline $\exp 44$ & 2.106 & 0 & 0 & 0 & 0.9343 & 0 & -0.5863 & 0.9914 & 0.736 & $\mathrm{~N}$ & $\mathrm{~N}$ \\
\hline $\exp 45$ & 0 & 0 & 0 & 0 & 1.3728 & 0 & 0 & 0.9971 & 0.2753 & $\mathrm{~N}$ & $\mathrm{~N}$ \\
\hline exp46 & 0 & 0 & 0.1588 & -0.17 & 1.788 & -1.0548 & 0 & 0.9987 & 0.1191 & $\mathrm{~N}$ & $\mathrm{~N}$ \\
\hline exp51 & -0.5089 & 0 & 0 & 0 & 1.6441 & -0.5496 & 0 & 0.9989 & 0.0945 & $\mathrm{Y}$ & $\mathrm{N}$ \\
\hline exp52 & 0 & 0 & 0 & 0 & 2.7746 & -2.72 & 0 & 0.908 & 8.101 & $\mathrm{~N}$ & $\mathrm{~N}$ \\
\hline exp53 & 0 & 0 & 0 & 0 & 2.3302 & 0 & 0 & 0.9472 & 4.1499 & $\mathrm{~N}$ & $\mathrm{~N}$ \\
\hline exp54 & 0 & 0 & 0 & 0 & 1.9597 & -0.7149 & 0 & 0.9983 & 0.1379 & $\mathrm{~N}$ & $\mathrm{~N}$ \\
\hline $\exp 55$ & 0 & 0 & 0 & 0 & 1.9919 & -0.8193 & 0 & 0.999 & 0.0804 & $\mathrm{~N}$ & $\mathrm{~N}$ \\
\hline exp56 & 0 & 0.4314 & 0 & 0 & 1.2853 & -0.5475 & 0 & 0.9975 & 0.2098 & $\mathrm{~N}$ & $\mathrm{Y}$ \\
\hline exp61 & 0 & 0 & -0.1818 & 0 & 1.7119 & 0 & 0 & 0.9981 & 0.189 & $\mathrm{~N}$ & $\mathrm{~N}$ \\
\hline exp62 & 0.9037 & 0 & 0 & 0 & 1.8094 & -0.8813 & 0 & 0.998 & 0.196 & $\mathrm{~N}$ & $\mathrm{~N}$ \\
\hline exp63 & 0 & 0 & 0 & 0 & 1.3038 & 0 & -0.6962 & 0.9972 & 0.282 & $\mathrm{Y}$ & $\mathrm{N}$ \\
\hline exp64 & 0.9764 & 0 & 0.1793 & 0 & 1.3818 & 0 & -0.7954 & 0.9982 & 0.1789 & $\mathrm{~N}$ & $\mathrm{~N}$ \\
\hline exp65 & 0.6059 & 0 & 0.4214 & 0 & 1.4628 & 0 & -0.5534 & 0.9991 & 0.0901 & $\mathrm{~N}$ & $\mathrm{~N}$ \\
\hline exp66 & 0.7244 & 0 & 0 & 0 & 1.3954 & 0 & -0.3728 & 0.9992 & 0.0767 & $\mathrm{~N}$ & $\mathrm{~N}$ \\
\hline exp71 & 0 & 0 & 0 & 0 & 2.9985 & -2.6571 & 0 & 0.9209 & 10.3634 & $\mathrm{~N}$ & $\mathrm{~N}$ \\
\hline exp72 & 1.0201 & 0 & 0 & 0 & 1.7136 & -0.7347 & 0 & 0.9985 & 0.1659 & $\mathrm{Y}$ & $\mathrm{N}$ \\
\hline $\exp 73$ & 0 & 0 & 0 & 0 & 1.5979 & 0 & 0 & 0.9824 & 1.9608 & $\mathrm{~N}$ & $\mathrm{~N}$ \\
\hline exp74 & 0.7069 & 0 & 0 & 0.0517 & 2.0059 & -1.303 & 0 & 0.9988 & 0.1321 & $\mathrm{~N}$ & $\mathrm{~N}$ \\
\hline exp75 & 0 & 0 & 0 & 0 & 1.4831 & -0.5172 & 0 & 0.998 & 0.2326 & $\mathrm{~N}$ & $\mathrm{~N}$ \\
\hline exp76 & 0 & 0 & 0 & 0 & 1.4831 & -0.5172 & 0 & 0.998 & 0.2326 & $\mathrm{~N}$ & $\mathrm{~N}$ \\
\hline exp81 & 0 & 0 & 0 & 0 & 1.8571 & 0 & 0 & 0.9538 & 6.3663 & $\mathrm{~N}$ & $\mathrm{~N}$ \\
\hline exp82 & 0 & 0 & 0 & 0 & 1.7091 & 0 & 0 & 0.9725 & 3.6825 & $\mathrm{~N}$ & $\mathrm{~N}$ \\
\hline $\exp 83$ & 0 & 0 & 0 & 0 & 1.7311 & 0 & 0 & 0.9777 & 2.903 & $\mathrm{~N}$ & $\mathrm{~N}$ \\
\hline exp84 & 0.4905 & 0.2501 & 0 & 0.0555 & 1.8692 & -1.3119 & 0 & 0.9992 & 0.0993 & Y & $\mathrm{N}$ \\
\hline exp85 & 0 & 0 & 0 & 0 & 1.8035 & -0.4334 & -0.2565 & 0.9993 & 0.0917 & $\mathrm{Y}$ & $\mathrm{N}$ \\
\hline exp86 & 0 & 0.6426 & 0 & 0 & 1.6909 & -1.6593 & 0.4216 & 0.9981 & 0.2508 & Y & $\mathrm{N}$ \\
\hline
\end{tabular}

Table A.2: Above is the result for estimating $p_{h, t}^{e}=c+\sum_{i=1}^{3} o_{i} p_{t-i}+\sum_{i=1}^{3} s_{i} p_{h, t-i}^{e}+\nu_{t}$ for the positive feedback treatment. The first column shows the participant number. The second to eights column shows the estimated coefficients. We start from the largest possible model and drop all the coefficients that are not significant at $5 \%$ level. The ninth and tenth columns show the $R^{2}$ and $M S E$ of the regressions. The twelfth shows whether we reject the null hypothesis of no breakpoint in the Chow test. 


\begin{tabular}{|c|c|c|c|c|c|c|}
\hline Part. & $\delta$ & $p-$ value & R squared & MSE & $\mathrm{AC}$ & Chow \\
\hline exp11 & -0.3139 & 0.0000 & 0.9414 & 5.5581 & $Y$ & $\mathrm{~N}$ \\
\hline exp12 & -0.2974 & 0.0000 & 0.9447 & 4.8722 & $\mathrm{~N}$ & Y \\
\hline exp13 & -0.4916 & 0.0000 & 0.9567 & 3.7767 & $\mathrm{~N}$ & Y \\
\hline exp14 & -0.4161 & 0.0000 & 0.8040 & 14.7437 & $\mathrm{Y}$ & Y \\
\hline exp15 & -0.4248 & 0.0000 & 0.8942 & 8.9993 & $\mathrm{~N}$ & Y \\
\hline exp16 & -0.2606 & 0.0000 & 0.9522 & 4.7818 & $\mathrm{~N}$ & $\mathrm{Y}$ \\
\hline exp21 & -0.2618 & 0.0000 & 0.9380 & 5.4525 & $\mathrm{Y}$ & $\mathrm{N}$ \\
\hline exp22 & -0.4877 & 0.0000 & 0.9937 & 0.5489 & Y & $\mathrm{N}$ \\
\hline exp23 & -0.2057 & 0.0000 & 0.9731 & 2.3426 & Y & Y \\
\hline exp24 & -0.2962 & 0.0000 & 0.9796 & 1.8632 & $\mathrm{~N}$ & $\mathrm{Y}$ \\
\hline exp25 & -0.6046 & 0.0000 & 0.8490 & 12.0504 & $\mathrm{Y}$ & $\mathrm{N}$ \\
\hline exp26 & 0.0055 & 0.8252 & 0.9779 & 2.1271 & $\mathrm{Y}$ & $\mathrm{N}$ \\
\hline exp31 & -0.1867 & 0.0000 & 0.9710 & 2.7068 & Y & $\mathrm{Y}$ \\
\hline exp32 & -0.4345 & 0.0000 & 0.8884 & 8.5564 & Y & Y \\
\hline exp33 & -0.2399 & 0.0000 & 0.9851 & 1.3797 & Y & Y \\
\hline exp34 & -0.2872 & 0.0000 & 0.9971 & 0.2599 & $\mathrm{~N}$ & $\mathrm{Y}$ \\
\hline exp35 & -0.4046 & 0.0000 & 0.8429 & 11.1724 & $\mathrm{Y}$ & $\mathrm{N}$ \\
\hline exp36 & -0.3318 & 0.0000 & 0.9473 & 5.1029 & $\mathrm{~N}$ & $\mathrm{Y}$ \\
\hline exp41 & -0.0970 & 0.0466 & 0.8959 & 9.2903 & $\mathrm{Y}$ & $\mathrm{N}$ \\
\hline exp42 & -0.5674 & 0.0000 & 0.8625 & 11.5414 & Y & $\mathrm{N}$ \\
\hline $\exp 43$ & -0.1650 & 0.0337 & 0.7618 & 23.6035 & Y & $\mathrm{N}$ \\
\hline $\exp 44$ & -0.3157 & 0.0000 & 0.9316 & 5.9790 & Y & Y \\
\hline exp45 & -0.1842 & 0.0000 & 0.9498 & 4.6031 & $\mathrm{Y}$ & $\mathrm{Y}$ \\
\hline exp46 & -0.3004 & 0.0000 & 0.8967 & 8.3406 & Y & Y \\
\hline exp51 & -0.4105 & 0.0000 & 0.9234 & 6.3143 & $\mathrm{~N}$ & Y \\
\hline exp52 & -0.3596 & 0.0000 & 0.9303 & 5.9393 & $\mathrm{Y}$ & $\mathrm{Y}$ \\
\hline exp53 & -0.7249 & 0.0000 & 0.8648 & 11.4676 & $\mathrm{Y}$ & $\mathrm{N}$ \\
\hline exp54 & -0.2939 & 0.0000 & 0.9212 & 7.0731 & $\mathrm{~N}$ & Y \\
\hline $\exp 55$ & -0.3160 & 0.0000 & 0.9577 & 3.6575 & $\mathrm{Y}$ & Y \\
\hline exp56 & -0.3272 & 0.0000 & 0.8064 & 19.4969 & $\mathrm{~N}$ & $\mathrm{~N}$ \\
\hline exp61 & -0.4027 & 0.0000 & 0.8237 & 15.4160 & $\mathrm{Y}$ & $\mathrm{N}$ \\
\hline exp62 & -0.0004 & 0.9938 & 0.8785 & 14.2253 & Y & $\mathrm{N}$ \\
\hline exp63 & -0.0744 & 0.0594 & 0.9012 & 10.2230 & $\mathrm{Y}$ & $\mathrm{N}$ \\
\hline exp64 & 0.0327 & 0.6024 & 0.8072 & 25.8189 & $\mathrm{~N}$ & $\mathrm{~N}$ \\
\hline exp65 & -0.5394 & 0.0000 & 0.5076 & 51.8923 & $\mathrm{~N}$ & Y \\
\hline exp66 & -0.4915 & 0.0000 & 0.5940 & 30.6449 & $\mathrm{Y}$ & $\mathrm{N}$ \\
\hline exp71 & -0.2521 & 0.0000 & 0.9153 & 7.1180 & $\mathrm{~N}$ & Y \\
\hline exp72 & -0.2285 & 0.0000 & 0.9332 & 5.6794 & $\mathrm{~N}$ & Y \\
\hline exp73 & -0.2731 & 0.0000 & 0.9839 & 1.3788 & $\mathrm{~N}$ & $\mathrm{Y}$ \\
\hline exp74 & -0.2395 & 0.0000 & 0.9685 & 2.6047 & Y & Y \\
\hline exp75 & -0.4561 & 0.0000 & 0.9866 & 1.2240 & $\mathrm{Y}$ & Y \\
\hline exp76 & -0.4632 & 0.0000 & 0.9029 & 7.5983 & Y & Y \\
\hline exp81 & -0.3677 & 0.0000 & 0.9548 & 4.0075 & $\mathrm{Y}$ & $\mathrm{Y}$ \\
\hline exp82 & -0.4979 & 0.0000 & 0.8721 & 9.8164 & Y & $\mathrm{N}$ \\
\hline exp83 & -0.1721 & 0.0000 & 0.9543 & 4.3523 & $\mathrm{~N}$ & $\mathrm{~N}$ \\
\hline exp84 & -0.1567 & 0.0000 & 0.9771 & 2.1902 & $\mathrm{Y}$ & Y \\
\hline exp85 & -0.3804 & 0.0000 & 0.9647 & 2.9116 & Y & $\mathrm{N}$ \\
\hline exp86 & -0.3396 & 0.0000 & 0.9664 & 2.7938 & $\mathrm{~N}$ & $\mathrm{Y}$ \\
\hline
\end{tabular}

Table A.3: Above is the result of estimating $p_{h, t}^{e}=p_{t-1}+\gamma\left(p_{t-1}-p_{t-2}\right)$ (trend rule) for the negative feedback treatment.The second and third column shows the estimated coefficients and associated $p$-value. The fourth and fifth columns show the $R^{2}$ and $M S E$ of the regressions. The sixth and seventh shows whether the residual of the regression has serial correlation within 10 lags, and we reject the null hypothesis of no breakpoint in the Chow test. 


\begin{tabular}{|c|c|c|c|c|c|c|}
\hline Part. & $\delta$ & $p-$ value & $\mathrm{R}$ squared & MSE & $\mathrm{AC}$ & Chow \\
\hline exp11 & 0.7382 & 0.0000 & 0.9968 & 0.1507 & $\mathrm{~N}$ & $\mathrm{Y}$ \\
\hline $\exp 12$ & 0.7392 & 0.0000 & 0.9960 & 0.1835 & Y & Y \\
\hline exp13 & 0.6958 & 0.0000 & 0.9979 & 0.1002 & Y & $\mathrm{Y}$ \\
\hline exp14 & 0.8616 & 0.0000 & 0.9969 & 0.1430 & Y & $\mathrm{Y}$ \\
\hline exp15 & 0.3908 & 0.0000 & 0.9962 & 0.1809 & Y & $\mathrm{Y}$ \\
\hline exp16 & 0.6222 & 0.0000 & 0.9969 & 0.1399 & Y & Y \\
\hline $\exp 21$ & 0.6801 & 0.0000 & 0.9939 & 0.0779 & $\mathrm{Y}$ & Y \\
\hline $\exp 22$ & -0.8371 & 0.2010 & 0.1562 & 36.6695 & $\mathrm{~N}$ & $\mathrm{~N}$ \\
\hline $\exp 23$ & 0.4753 & 0.0000 & 0.9788 & 0.2571 & Y & $\mathrm{Y}$ \\
\hline exp24 & -0.4522 & 0.0000 & 0.9260 & 0.8429 & Y & $\mathrm{Y}$ \\
\hline $\exp 25$ & -0.0823 & 0.4719 & 0.8883 & 1.1204 & Y & Y \\
\hline $\exp 26$ & 0.1501 & 0.0021 & 0.9813 & 0.2029 & $\mathrm{~N}$ & $\mathrm{Y}$ \\
\hline exp31 & 0.8568 & 0.0000 & 0.9981 & 0.1680 & $\mathrm{Y}$ & $\mathrm{Y}$ \\
\hline exp32 & 0.9554 & 0.0000 & 0.9978 & 0.1859 & Y & $\mathrm{N}$ \\
\hline exp33 & 0.8212 & 0.0000 & 0.9938 & 0.5325 & $\mathrm{~N}$ & $\mathrm{~N}$ \\
\hline exp34 & 0.8932 & 0.0000 & 0.9981 & 0.1589 & Y & $\mathrm{N}$ \\
\hline exp35 & 0.8957 & 0.0000 & 0.9986 & 0.1207 & Y & $\mathrm{Y}$ \\
\hline exp36 & 0.7838 & 0.0000 & 0.9940 & 0.5239 & $\mathrm{~N}$ & $\mathrm{~N}$ \\
\hline $\exp 41$ & 0.8698 & 0.0000 & 0.9982 & 0.1606 & $\mathrm{Y}$ & Y \\
\hline $\exp 42$ & 0.9460 & 0.0000 & 0.9990 & 0.0841 & Y & $\mathrm{Y}$ \\
\hline exp43 & 0.9623 & 0.0000 & 0.9981 & 0.1712 & $\mathrm{~N}$ & $\mathrm{~N}$ \\
\hline exp44 & 0.5047 & 0.0000 & 0.9895 & 0.8690 & $\mathrm{~N}$ & $\mathrm{~N}$ \\
\hline $\exp 45$ & 0.6695 & 0.0000 & 0.9941 & 0.5544 & $\mathrm{Y}$ & $\mathrm{Y}$ \\
\hline $\exp 46$ & 0.8693 & 0.0000 & 0.9978 & 0.1970 & Y & $\mathrm{Y}$ \\
\hline exp51 & 0.7203 & 0.0000 & 0.9987 & 0.1096 & $\mathrm{~N}$ & $\mathrm{~N}$ \\
\hline exp52 & 0.3944 & 0.1220 & 0.9000 & 8.5280 & $\mathrm{~N}$ & $\mathrm{~N}$ \\
\hline $\exp 53$ & 0.7358 & 0.0001 & 0.9396 & 4.6080 & $\mathrm{~N}$ & $\mathrm{~N}$ \\
\hline exp54 & 0.9420 & 0.0000 & 0.9982 & 0.1435 & $\mathrm{~N}$ & $\mathrm{~N}$ \\
\hline $\exp 55$ & 0.9244 & 0.0000 & 0.9989 & 0.0903 & $\mathrm{~N}$ & $\mathrm{~N}$ \\
\hline exp56 & 0.6184 & 0.0000 & 0.9966 & 0.2738 & $\mathrm{~N}$ & $\mathrm{~N}$ \\
\hline $\exp 61$ & 0.9531 & 0.0000 & 0.9974 & 0.2564 & $\mathrm{~N}$ & $\mathrm{~N}$ \\
\hline exp62 & 0.8945 & 0.0000 & 0.9975 & 0.2394 & $\mathrm{~N}$ & $\mathrm{Y}$ \\
\hline exp63 & 0.7527 & 0.0000 & 0.9965 & 0.3420 & $\mathrm{~N}$ & $\mathrm{Y}$ \\
\hline exp64 & 0.9337 & 0.0000 & 0.9975 & 0.2426 & $\mathrm{~N}$ & $\mathrm{Y}$ \\
\hline $\exp 65$ & 0.7661 & 0.0000 & 0.9984 & 0.1620 & Y & $\mathrm{N}$ \\
\hline $\exp 66$ & 0.8887 & 0.0000 & 0.9984 & 0.1607 & $\mathrm{~N}$ & $\mathrm{Y}$ \\
\hline exp71 & 0.8002 & 0.0005 & 0.9156 & 10.7493 & $\mathrm{~N}$ & $\mathrm{~N}$ \\
\hline exp72 & 0.9020 & 0.0000 & 0.9978 & 0.2426 & $\mathrm{Y}$ & $\mathrm{N}$ \\
\hline exp73 & 0.6954 & 0.0000 & 0.9811 & 2.0516 & $\mathrm{~N}$ & $\mathrm{~N}$ \\
\hline exp74 & 0.9316 & 0.0000 & 0.9982 & 0.1938 & $\mathrm{Y}$ & $\mathrm{N}$ \\
\hline exp75 & 0.7416 & 0.0000 & 0.9973 & 0.3007 & $\mathrm{~N}$ & $\mathrm{Y}$ \\
\hline exp76 & 0.7416 & 0.0000 & 0.9973 & 0.3007 & $\mathrm{~N}$ & Y \\
\hline exp81 & 0.6981 & 0.0000 & 0.9530 & 6.3286 & $\mathrm{~N}$ & $\mathrm{~N}$ \\
\hline exp82 & 0.7556 & 0.0000 & 0.9715 & 3.7313 & $\mathrm{~N}$ & $\mathrm{~N}$ \\
\hline exp83 & 0.6985 & 0.0000 & 0.9750 & 3.1934 & $\mathrm{~N}$ & $\mathrm{~N}$ \\
\hline exp84 & 0.9352 & 0.0000 & 0.9983 & 0.2175 & $\mathrm{Y}$ & $\mathrm{Y}$ \\
\hline exp85 & 0.9403 & 0.0000 & 0.9991 & 0.1130 & $\mathrm{~N}$ & $\mathrm{~N}$ \\
\hline $\exp 86$ & 0.8256 & 0.0000 & 0.9968 & 0.4210 & Y & Y \\
\hline
\end{tabular}

Table A.4: Above is the result of estimating $p_{h, t}^{e}=p_{t-1}+\gamma\left(p_{t-1}-p_{t-2}\right)$ (trend rule) for the positive feedback treatment.The second and third column shows the estimated coefficients and associated $p$-value. The fourth and fifth columns show the $R^{2}$ and $M S E$ of the regressions. The sixth and seventh shows whether the residual of the regression has serial correlation within 10 lags, and we reject the null hypothesis of no breakpoint in the Chow test. 


\begin{tabular}{|c|c|c|c|c|c|c|}
\hline Part. & $\gamma$ & $p-$ value & $\mathrm{R}$ squared & MSE & $\mathrm{AC}$ & Chow \\
\hline $\exp 11$ & 0.9424 & 0.0000 & 0.9861 & 0.6602 & $\mathrm{Y}$ & $\mathrm{Y}$ \\
\hline exp12 & 1.1408 & 0.0000 & 0.9859 & 0.6492 & Y & $\mathrm{N}$ \\
\hline exp13 & 1.5178 & 0.0000 & 0.9907 & 0.4352 & Y & $\mathrm{Y}$ \\
\hline exp14 & 1.3952 & 0.0000 & 0.9841 & 0.7327 & Y & $\mathrm{N}$ \\
\hline exp15 & 0.9251 & 0.0000 & 0.9916 & 0.3962 & Y & $\mathrm{Y}$ \\
\hline exp16 & 0.5722 & 0.0000 & 0.9721 & 1.2868 & Y & Y \\
\hline $\exp 21$ & 1.0935 & 0.0000 & 0.9498 & 0.6491 & Y & $\mathrm{Y}$ \\
\hline exp22 & 1.0664 & 0.0000 & 0.1420 & 37.5080 & $\mathrm{~N}$ & $\mathrm{~N}$ \\
\hline exp23 & 1.2244 & 0.0000 & 0.9614 & 0.4724 & $\mathrm{Y}$ & $\mathrm{Y}$ \\
\hline exp24 & 0.7271 & 0.0000 & 0.9122 & 0.9999 & Y & $\mathrm{N}$ \\
\hline $\exp 25$ & 0.7102 & 0.0000 & 0.7858 & 2.2849 & $\mathrm{~N}$ & $\mathrm{~N}$ \\
\hline exp26 & 0.7515 & 0.0000 & 0.9626 & 0.4069 & Y & Y \\
\hline exp31 & 0.8823 & 0.0000 & 0.9767 & 2.0097 & Y & Y \\
\hline exp32 & 1.6048 & 0.0000 & 0.9734 & 2.2709 & Y & Y \\
\hline exp33 & 1.0810 & 0.0000 & 0.9747 & 2.1736 & Y & Y \\
\hline exp34 & 1.9355 & 0.0000 & 0.9789 & 1.7853 & Y & $\mathrm{N}$ \\
\hline exp35 & 1.6927 & 0.0000 & 0.9779 & 1.8903 & Y & $\mathrm{N}$ \\
\hline exp36 & 1.3980 & 0.0000 & 0.9782 & 1.8973 & Y & $\mathrm{N}$ \\
\hline exp41 & 0.9779 & 0.0000 & 0.9817 & 1.6436 & Y & Y \\
\hline exp42 & 0.9741 & 0.0000 & 0.9794 & 1.8161 & Y & $\mathrm{N}$ \\
\hline exp43 & 0.8763 & 0.0000 & 0.9783 & 1.9282 & Y & $\mathrm{N}$ \\
\hline exp44 & 1.0576 & 0.0000 & 0.9841 & 1.3211 & Y & $\mathrm{N}$ \\
\hline $\exp 45$ & 1.0338 & 0.0000 & 0.9845 & 1.4542 & Y & Y \\
\hline exp46 & 1.4682 & 0.0000 & 0.9830 & 1.5486 & Y & $\mathrm{N}$ \\
\hline exp51 & 1.1025 & 0.0000 & 0.9841 & 1.2888 & Y & Y \\
\hline exp52 & 0.8902 & 0.0000 & 0.8963 & 8.8466 & $\mathrm{~N}$ & $\mathrm{~N}$ \\
\hline exp53 & 1.8644 & 0.0000 & 0.9351 & 4.9498 & $\mathrm{~N}$ & $\mathrm{~N}$ \\
\hline exp54 & 1.3971 & 0.0000 & 0.9755 & 1.9568 & $\mathrm{Y}$ & $\mathrm{N}$ \\
\hline $\exp 55$ & 1.4030 & 0.0000 & 0.9781 & 1.7679 & Y & $\mathrm{N}$ \\
\hline exp56 & 1.0879 & 0.0000 & 0.9871 & 1.0317 & Y & Y \\
\hline exp61 & 0.9198 & 0.0000 & 0.9751 & 2.4283 & Y & Y \\
\hline exp62 & 1.6869 & 0.0000 & 0.9803 & 1.8727 & Y & $\mathrm{N}$ \\
\hline exp63 & 1.8255 & 0.0000 & 0.9872 & 1.2446 & $\mathrm{Y}$ & $\mathrm{Y}$ \\
\hline exp64 & 1.1373 & 0.0000 & 0.9776 & 2.2041 & Y & $\mathrm{N}$ \\
\hline exp65 & 1.7368 & 0.0000 & 0.9876 & 1.2279 & Y & $\mathrm{Y}$ \\
\hline exp66 & 1.5477 & 0.0000 & 0.9810 & 1.8593 & Y & $\mathrm{N}$ \\
\hline exp71 & 0.9172 & 0.0000 & 0.8994 & 12.8476 & $\mathrm{~N}$ & $\mathrm{~N}$ \\
\hline exp72 & 1.4850 & 0.0000 & 0.9739 & 2.8590 & $\mathrm{Y}$ & $\mathrm{Y}$ \\
\hline exp73 & 1.1846 & 0.0000 & 0.9670 & 3.6002 & Y & $\mathrm{N}$ \\
\hline exp74 & 0.9126 & 0.0000 & 0.9710 & 3.2125 & Y & Y \\
\hline exp75 & 1.4159 & 0.0000 & 0.9837 & 1.8377 & $\mathrm{Y}$ & $\mathrm{N}$ \\
\hline exp76 & 1.4159 & 0.0000 & 0.9837 & 1.8377 & $\mathrm{Y}$ & $\mathrm{N}$ \\
\hline exp81 & 0.9753 & 0.0000 & 0.9406 & 8.1480 & Y & $\mathrm{Y}$ \\
\hline exp82 & 0.9897 & 0.0000 & 0.9564 & 5.8048 & Y & $\mathrm{N}$ \\
\hline exp83 & 1.0138 & 0.0000 & 0.9615 & 4.9608 & Y & $\mathrm{N}$ \\
\hline exp84 & 0.6519 & 0.0000 & 0.9700 & 3.7406 & Y & $\mathrm{Y}$ \\
\hline exp85 & 1.0167 & 0.0000 & 0.9727 & 3.5355 & Y & Y \\
\hline exp86 & 1.1955 & 0.0000 & 0.9789 & 2.7769 & Y & $\mathrm{N}$ \\
\hline
\end{tabular}

Table A.5: Above is the result of estimating $p_{h, t}^{e}=p_{t-1}^{e}+w\left(p_{t-1}-p_{t-1}^{e}\right)$ (adaptive rule) for the negative feedback treatment.The second and third column shows the estimated coefficients and associated $p$-value. The fourth and fifth columns show the $R^{2}$ and $M S E$ of the regressions. The sixth and seventh shows whether the residual of the regression has serial correlation within 10 lags, and we reject the null hypothesis of no breakpoint in the Chow test. 


\begin{tabular}{|c|c|c|c|c|c|c|}
\hline Part. & $\gamma$ & $p-$ value & R squared & MSE & $\mathrm{AC}$ & Chow \\
\hline $\exp 11$ & 0.6293 & 0.0000 & 0.9575 & 4.0606 & $\mathrm{~N}$ & $\mathrm{~N}$ \\
\hline exp12 & 0.7760 & 0.0000 & 0.9282 & 6.3727 & Y & Y \\
\hline $\exp 13$ & 0.5547 & 0.0000 & 0.9171 & 7.3071 & Y & Y \\
\hline exp14 & 0.4525 & 0.0000 & 0.9106 & 6.9727 & $\mathrm{~N}$ & Y \\
\hline $\exp 15$ & 0.6980 & 0.0000 & 0.8539 & 12.7427 & Y & $\mathrm{Y}$ \\
\hline exp16 & 0.7414 & 0.0000 & 0.9505 & 4.9973 & $\mathrm{~N}$ & Y \\
\hline exp21 & 0.6775 & 0.0000 & 0.9511 & 4.3043 & $\mathrm{~N}$ & $\mathrm{~N}$ \\
\hline $\exp 22$ & 0.4953 & 0.0000 & 0.9664 & 2.9461 & Y & $\mathrm{N}$ \\
\hline $\exp 23$ & 0.7426 & 0.0000 & 0.9832 & 1.4899 & $\mathrm{~N}$ & Y \\
\hline $\exp 24$ & 0.7894 & 0.0000 & 0.9556 & 4.1091 & Y & Y \\
\hline $\exp 25$ & 0.3198 & 0.0000 & 0.8868 & 9.0512 & $\mathrm{~N}$ & Y \\
\hline $\exp 26$ & 0.9890 & 0.0000 & 0.9777 & 2.1630 & $\mathrm{Y}$ & $\mathrm{N}$ \\
\hline exp31 & 0.8846 & 0.0000 & 0.9598 & 3.8891 & $\mathrm{Y}$ & $\mathrm{Y}$ \\
\hline exp32 & 0.4645 & 0.0000 & 0.9431 & 4.4836 & $\mathrm{~N}$ & Y \\
\hline exp33 & 0.7463 & 0.0000 & 0.9867 & 1.2406 & $\mathrm{~N}$ & Y \\
\hline $\exp 34$ & 0.6691 & 0.0000 & 0.9945 & 0.4960 & $\mathrm{~N}$ & Y \\
\hline exp35 & 0.3911 & 0.0000 & 0.9426 & 4.0834 & $\mathrm{~N}$ & Y \\
\hline exp36 & 0.7070 & 0.0000 & 0.9347 & 6.5234 & $\mathrm{Y}$ & Y \\
\hline exp41 & 0.8154 & 0.0000 & 0.9146 & 7.6203 & $\mathrm{Y}$ & $\mathrm{Y}$ \\
\hline exp42 & 0.3493 & 0.0000 & 0.9141 & 7.2730 & $\mathrm{~N}$ & $\mathrm{~N}$ \\
\hline $\exp 43$ & 0.7922 & 0.0000 & 0.7791 & 21.9006 & $\mathrm{~N}$ & $\mathrm{~N}$ \\
\hline $\exp 44$ & 0.6362 & 0.0000 & 0.9425 & 5.0350 & Y & Y \\
\hline $\exp 45$ & 0.7761 & 0.0000 & 0.9588 & 3.7798 & $\mathrm{~N}$ & Y \\
\hline exp46 & 0.6941 & 0.0000 & 0.9096 & 7.3088 & $\mathrm{~N}$ & $\mathrm{Y}$ \\
\hline exp51 & 0.5600 & 0.0000 & 0.8633 & 11.7131 & $\mathrm{Y}$ & $\mathrm{N}$ \\
\hline exp52 & 0.6240 & 0.0000 & 0.9377 & 5.3217 & $\mathrm{Y}$ & $\mathrm{Y}$ \\
\hline $\exp 53$ & 0.2863 & 0.0000 & 0.8933 & 9.0539 & Y & $\mathrm{N}$ \\
\hline $\exp 54$ & 0.7174 & 0.0000 & 0.9142 & 7.7120 & Y & Y \\
\hline $\exp 55$ & 0.6522 & 0.0000 & 0.9604 & 3.4285 & Y & Y \\
\hline exp56 & 0.7583 & 0.0000 & 0.7791 & 22.2554 & $\mathrm{~N}$ & $\mathrm{~N}$ \\
\hline exp61 & 0.5449 & 0.0000 & 0.8507 & 13.3092 & $\mathrm{Y}$ & $\mathrm{N}$ \\
\hline $\exp 62$ & 0.9626 & 0.0000 & 0.8811 & 14.0468 & $\mathrm{~N}$ & $\mathrm{~N}$ \\
\hline $\exp 63$ & 0.8725 & 0.0000 & 0.9116 & 9.2224 & Y & $\mathrm{N}$ \\
\hline exp64 & 1.0217 & 0.0000 & 0.8077 & 25.9003 & $\mathrm{~N}$ & $\mathrm{~N}$ \\
\hline exp65 & 0.5962 & 0.0000 & 0.4571 & 57.8418 & $\mathrm{~N}$ & $\mathrm{~N}$ \\
\hline exp66 & 0.3470 & 0.0000 & 0.8561 & 10.8682 & $\mathrm{Y}$ & $\mathrm{N}$ \\
\hline exp71 & 0.6960 & 0.0000 & 0.9306 & 5.9552 & $\mathrm{~N}$ & Y \\
\hline exp72 & 0.7421 & 0.0000 & 0.9402 & 5.2224 & $\mathrm{~N}$ & Y \\
\hline $\exp 73$ & 0.6880 & 0.0000 & 0.9887 & 0.9743 & Y & Y \\
\hline exp74 & 0.7134 & 0.0000 & 0.9772 & 1.9062 & $\mathrm{~N}$ & Y \\
\hline exp75 & 0.5223 & 0.0000 & 0.9693 & 2.8093 & Y & $\mathrm{N}$ \\
\hline exp76 & 0.3999 & 0.0000 & 0.9635 & 2.8652 & Y & $\mathrm{Y}$ \\
\hline exp81 & 0.6569 & 0.0000 & 0.9312 & 6.1064 & Y & $\mathrm{Y}$ \\
\hline exp82 & 0.4561 & 0.0000 & 0.9075 & 7.1060 & $\mathrm{~N}$ & Y \\
\hline exp83 & 0.8267 & 0.0000 & 0.9551 & 4.2800 & $\mathrm{~N}$ & Y \\
\hline exp84 & 0.8598 & 0.0000 & 0.9730 & 2.5944 & Y & Y \\
\hline exp85 & 0.5453 & 0.0000 & 0.9825 & 1.4443 & $\mathrm{~N}$ & $\mathrm{~N}$ \\
\hline $\exp 86$ & 0.6126 & 0.0000 & 0.9703 & 2.4757 & Y & Y \\
\hline
\end{tabular}

Table A.6: Above is the result of estimating $p_{h, t}^{e}=p_{t-1}^{e}+w\left(p_{t-1}-p_{t-1}^{e}\right)$ (adaptive rule) for the positive feedback treatment. The second and third column shows the estimated coefficients and associated $p$-value. The fourth and fifth columns show the $R^{2}$ and $M S E$ of the regressions. The sixth and seventh shows whether the residual of the regression has serial correlation within 10 lags, and we reject the null hypothesis of no breakpoint in the Chow test. 